\title{
Intracortical Myelin Links with Performance Variability across the Human Lifespan: Results from T1- and T2- Weighted MRI Myelin Mapping and Diffusion Tensor Imaging
}

\author{
Håkon Grydeland, Kristine B. Walhovd, Christian K. Tamnes, Lars T. Westlye, and Anders M. Fjell \\ Research Group for Lifespan Changes in Brain and Cognition, Department of Psychology, University of Oslo, 0317 Oslo, Norway
}

Cerebral myelin maturation and aging-related degradation constitute fundamental features of human brain integrity and functioning. Although mostly studied in the white matter, the cerebral cortex contains significant amounts of myelinated axons. However, how intracortical myelin content evolves during development, decays in aging, and links with cognition remain poorly understood. Several studies have shown the potential of mapping myelin in the cortex by use of T1-weighted (T1w) and T2-weighted (T2w) magnetic resonance imaging signal intensity, which show inverse sensitivity to myelin. Here, we characterized cortical myelin in 339 participants $8-83$ years of age using a recently introduced T1w/T2 $w$ ratio myelin mapping technique and mean diffusivity (MD) from diffusion tensor imaging. To test for cognitive correlates, we used intraindividual variability (IIV) in performance during a speeded task, a measure recently associated with white matter integrity. The results showed that intracortical myelin maturation was ongoing until the late 30 s, followed by 20 relative stable years before declining from the late 50 s. For MD, U-shaped paths showing similar patterns were observed, but with fewer maturational effects in some regions. IIV was correlated with both T1w/T2w ratio and MD, mainly indicating that the higher degree of intracortical myelin is associated with greater performance stability. The relations were more prominent with advancing age, suggesting that aging-related cortical demyelination contributes to increased IIV. The T1w/T2w ratio myelin-mapping technique thus seems sensitive to intracortical myelin content in normal development and aging, relates to cognitive functioning, and might constitute an important future tool in mapping normal and clinical brain changes.

\section{Introduction}

Although most prominent in the white matter (WM) of the brain, myelinated axons abound within the cerebral cortex (Vogt, 1910; Nieuwenhuys, 2013). Cortical myelin maturation and aging-related degradation thus likely constitute fundamental features of how the brain evolves and devolves ontogenetically. Histology studies have shown protracted development of intracortical myelination in humans (Yakovlev and Lecours, 1967 ) and aging-related cortical myelin alterations in primates (Feldman and Peters, 1998). The observation of prolonged myelination makes intracortical axons particularly interesting to investigate in a lifespan perspective (Bartzokis, 2004). However,

Received July 2, 2013; revised Sept. 30, 2013; accepted 0ct. 23, 2013.

Author contributions:H.G., K.W., and A.M.F. designed research;H.G., C.K.T., and L.T.W. performed research;H.G.,

C.K.T., L.T.W., and A.M.F. analyzed data; H.G., K.W., C.K.T., L.T.W., and A.M.F. wrote the paper.

This work was supported by The Norwegian Research Council (to K.B.W., L.T.W., and A.M.F.) and the European Research Council Starting Grant Scheme (to K.B.W. and A.M.F.).

The authors declare no competing financial interests.

Correspondence should be addressed to Håkon Grydeland, Department of Psychology, University of Oslo, P0 Box 1094, Blindern, 0317 0slo, Norway. E-mail: hakon.grydeland@psykologi.uio.no.

L.T. Westlye's present address: Norwegian Centre for Mental Disorders Research (NORMENT), K.G. Jebsen Centre for Psychosis Research, Division of Mental Health and Addiction, Oslo University Hospital, and Department of Psychology, University of 0slo, 0317 0slo, Norway.

DOI:10.1523/JNEUROSCI.2811-13.2013

Copyright $\odot 2013$ the authors $\quad 0270-6474 / 13 / 3318618-13 \$ 15.00 / 0$ attempts to map intracortical lifespan trajectories of myelin in vivo are lacking and a link with cognitive functioning has not been established.

Magnetic resonance imaging (MRI) facilitates in vivo noninvasive whole-brain characterization of large samples. How cortical integrity changes with age and relates to cognitive abilities have in MRI studies usually been investigated using cortical thickness or volume (Bartzokis et al., 2001; Sowell et al., 2003; Gogtay et al., 2004; Carreiras et al., 2009; Fjell et al., 2009; Tamnes et al., 2010; Kochunov et al., 2011; Westlye et al., 2011). Although putatively also partly reflecting myelin (Paus, 2005), these measures have limited neurobiological specificity. Indices derived from diffusion tensor imaging (DTI) have been associated more directly, although far from exclusively (Beaulieu, 2002), with myelin (Song et al., 2002), but have primarily been used to map WM or subcortical gray matter (GM) structures (Westlye et al., 2010a; Kochunov et al., 2011; Lebel and Beaulieu, 2011).

Interestingly, cortical regions can be delineated based on myelin content by use of intrinsic signal intensity properties of T1-weighted (T1w) or T2-weighted (T2w) MRI (Yoshiura et al., 2000; Sigalovsky et al., 2006). A recent study created detailed surface-based cortical myelin maps by taking a ratio of T1w and T2w image intensities to correct for the MRI-related image intensity bias field and to increase the contrast to noise ratio for myelin (Glasser and Van Essen, 2011). 
Table 1. Sample characteristics

\begin{tabular}{llllll}
\hline & N (\% female) & Age, $y$ & Education, $y^{a}$ & MMSE $^{b}$ & \multicolumn{1}{c}{ Full-scale IQ } \\
\hline Young & $85(50.6)$ & $14.7(3.3 ; 8.4-19.7)$ & NA & NA & $108.9(9.9 ; 91-132)$ \\
Adults & $254(57.3)$ & $48.8(17.0 ; 19.7-83.1)$ & $15.7(2.8 ; 4-26)$ & $29.2(0.8 ; 26-30)$ & $114.2(8.6 ; 92-141)$ \\
Total & $339(55.5)$ & $40.3(20.9 ; 8.4-83.1)$ & $15.7(2.8 ; 4-26)$ & $29.2(0.8 ; 26-30)$ & $112.8(9.2 ; 91-141)$ \\
\hline
\end{tabular}

Data are shown as mean (SD; min-max) if not otherwise indicated. NA, not applicable.

${ }^{a}$ Missing from two adult subjects.

${ }^{b}$ Available for subjects $>40$ years of age.

Therefore, the cortex was parcellated based on local differences in myelin content derived from MRI alone. This myelin-mapping approach allows for addressing tantalizing questions of how intracortical myelin influences cognitive functioning and how this relation unfolds across the lifespan. Recently, we demonstrated an association between WM integrity and intraindividual variability (IIV) in performance during a speeded performance task (Fjell et al., 2011; Tamnes et al., 2012). However, whether these effects relate specifically to the WM fiber pathways connecting distributed brain regions remain unknown; that degree of cortical myelin contributes to the individual differences in performance stability constitutes an intriguing but untested hypothesis.

The present study aimed to: (1) delineate intracortical myelination through the lifespan using the $\mathrm{T} 1 \mathrm{w} / \mathrm{T} 2 \mathrm{w}$ ratio launched by Glasser and Van Essen (2011) and (2) assess the association between cognitive performance variability and intracortical myelin grade. In addition, all analyses were also performed with DTI-derived mean diffusivity (MD) values from the same cortical areas. We hypothesize an inverted U-shaped trajectory of cortical myelin across the lifespan and that higher myelin grade yields less performance variability, particularly with advancing age (Fjell et al., 2011).

\section{Materials and Methods}

Subjects. The Regional Committee for Medical and Health Research Ethics approved the study. We drew the sample from the first wave of two ongoing longitudinal projects by the Research Group for Lifespan Changes in Brain and Cognition at the University of Oslo, namely "Neurocognitive Development" and "Cognition and Plasticity through the Lifespan." Participants were recruited through newspaper ads, among students and employees at the University of Oslo, and from local schools. Further details regarding recruitment and enrollment were described previously (Westlye et al., 2009a; Tamnes et al., 2010). Participants $<12$ years of age gave oral informed consent, whereas written informed consent was obtained from all participants $>12$ years of age and from a parent or guardian for participants $<18$ years of age. Participants $<16$ years of age and their parents were screened with standardized health interviews to ascertain eligibility; we required participants to be right-handed, fluent Norwegian speakers, and have normal or corrected to normal vision and hearing. Self-reported (screening interview at enrollment) neurological or psychiatric conditions known to affect normal cerebral functioning, including clinically significant stroke, traumatic brain injury, untreated hypertension, diabetes, use of psychoactive drugs within the last 2 years, or worries concerning own cognitive status including memory function, were exclusion criteria. All participants $>20$ years of age scored $<16$ on the Beck Depression Inventory (Beck and Steer, 1987) and participants $>40$ years of age scored $\geq 26$ on the Mini Mental State Examination (Folstein et al., 1975). A neuroradiologist evaluated and deemed all scans free of significant injuries or conditions in all but three cases, which were excluded. Of the remaining 400 participants satisfying these criteria, 61 subjects were excluded due to incomplete records (missing behavioral assessment or T1w, T2w, or DTI scans), motion-compromised MRI data (determined by visual inspection), age (one participant exceeded 90 years, creating a gap of missing data points on the otherwise continuous age scale), or suboptimal task focus or performance (in the young subsample) defined as $<80 \%$ accuracy in the congruent trials or a nonsignificant congruency effect on reaction time (RT) in correct trials (i.e., faster responses for congruent compared with incongruent trials; see description of task below). The suboptimal task per- formance criteria resulted in the exclusion of 9 participants ( mean age $=11.1$ years, $\mathrm{SD}=2.3$ years, min-max $8.8-14.5$ years) and were applied in the young subsample to ensure that participants having difficulties in performing the task adequately did not unduly influence the brain-behavior associations. In total, we included 339 participants (188 females, 55.5\%; Table 1), mean age $=40.3, \mathrm{SD}=20.9$, min-max age $=8.4-83.1$. A two-sample $t$ test revealed no significant differences in age between females (mean age $=41$, $\mathrm{SD}=20.3$ ) and males (mean age $=39.6, \mathrm{SD}=21.8 ; t_{(337)}=0.624, p=0.53$ ). To facilitate comparisons with our previous studies using overlapping samples (Fjell et al., 2011; Tamnes et al., 2012), we created similar age range subsamples: young $(n=85,43$ females [50.6\%], mean age $=14.7, \mathrm{SD}=3.3$, min-max age $=8.4-19.7)$ and adults $(n=254,146$ females [57.3\%], mean age $=48.8, \mathrm{SD}=17.0$, min-max age $=19.7-83.1)$.

General cognitive abilities were assessed by Wechsler Abbreviated Scale of Intelligence (Wechsler, 1999). Estimated mean full-scale intelligence quotient (FIQ) for the entire sample was 112.8 (range $=91-141, \mathrm{SD}=9.2$ ).

Image acquisition. MRI was performed using a 12-channel head coil on a $1.5 \mathrm{~T}$ Siemens Avanto scanner at Oslo University Hospital Rikshospitalet. The T1w volumes were acquired using a 3D T1w magnetization-prepared rapid gradient echo $($ MPRAGE; $\mathrm{TR}=2400 \mathrm{~ms}, \mathrm{TE}=3.61 \mathrm{~ms}, \mathrm{TI}=1000 \mathrm{~ms}$, $8^{\circ}$ flip angle, bandwidth $=180 \mathrm{~Hz} /$ pixel, FOV $=240 \mathrm{~mm}$, matrix $=192 \times$ $192 \times 160,1.25 \times 1.25 \times 1.2 \mathrm{~mm}$ voxels). For the T2w volumes, a 3D T2w sampling perfection with application-optimized contrasts using different flip angle evolutions (SPACE, TR $=3390 \mathrm{~ms}$, TE $=388 \mathrm{~ms}$, variable flip angle, bandwidth $=650 \mathrm{~Hz} /$ pixel, FOV $=256 \mathrm{~mm}, 1 \mathrm{~mm}$ isotropic voxels) was used; 155 participants $(46.6 \%)$ were scanned with a $204 \times 256 \times 176$ matrix (mean age $=37.5, \mathrm{SD}=19.0$, min- $\max =8.4-60.6)$, and 151 participants $(53.4 \%)$ were scanned with a $256 \times 256 \times 176$ matrix $($ mean age $=$ $42.8, \mathrm{SD}=22.3$, $\min -\max =8.5-83.1$ ). All other $\mathrm{T} 2 \mathrm{w}$ parameters were equal. Both T1w and T2w scans were acquired sagittally.

The DTI was performed with a single-shot twice-refocused spin-echo echo planar imaging pulse sequence with 30 diffusion-sensitized gradient directions $\left(\mathrm{TR}=8200 \mathrm{~ms}, \mathrm{TE}=82 \mathrm{~ms}\right.$, b-value $=700 \mathrm{~s} / \mathrm{mm}^{2}, 2 \mathrm{~mm}$ isotropic voxels, and 64 axial slices). The sequence, optimized to minimize eddy current-induced distortions (Reese et al., 2003), was repeated in 2 successive runs with $10 \mathrm{~b}=0$ and 30 diffusion weighted images collected per run.

Preprocessing. All datasets were processed and analyzed at the Neuroimaging Analysis Laboratory, Research Group for Lifespan Changes in Brain and Cognition, University of Oslo. The original unresampled T1w volumes were processed using the Freesurfer 5.1 suite (http://surfer.nmr. mgh.harvard.edu), performing brain extraction, intensity normalization, automated tissue segmentation, surface-based cortical thickness estimations, generation of white and pial surfaces, surface topology correction, automated whole-brain segmentation, and spherical interindividual surface alignment (Sled et al., 1998; Dale et al., 1999; Fischl et al., 1999a; Fischl and Dale, 2000; Fischl et al., 2002; Fischl et al., 2004a; Fischl et al., 2004b; Ségonne et al., 2004).

The T2w image was registered to the unresampled T1w image by using Freesurfer's bbregister, a within-subject, cross-modal registration using a boundary-based cost function constrained to be six degrees of freedom (rigid body; Greve and Fischl, 2009). The resulting linear transform was applied by use of FSL's applywarp tool using spline interpolation which minimize the white matter and CSF contamination of GM voxels that would result from the volumetric blurring inherent in trilinear interpolation (Glasser and Van Essen, 2011).

The T1w volume was then divided on the aligned preprocessed T2 $\mathrm{w}$ volume, creating a T1w/T2w ratio volume. Based on recent work on T1w signal 
intensity by us (Westlye et al., 2009b) and others (Panizzon et al., 2012), we sampled T1w/T2w values vertex-wise at a distance of $0.2 \mathrm{~mm}$ into the GM from the WM/GM boundary using Freesurfer's mri_vol2surf tool, yielding $\mathrm{T} 1 \mathrm{w} / \mathrm{T} 2 \mathrm{w}$ ratio surfaces. This fixed distance procedure diverge from the midthickness-based average approach taken by Glasser and Van Essen (2011). However, in the present data, after inspecting age-trajectory curves based on average values (sampled at 20 steps along the normal spaced at 0.05 fraction intervals), we found that a fixed distance approach was less prone to interactions of age, thickness, and intensity; such interaction effects would be expected to be more readily present when studying lifespan trajectories compared with the more narrow age span in the samples used by Glasser and Van Essen of mean age $22 \pm 6$ years and $42 \pm 11$ years. Further, as we previously have found effects of WM microstructure on IIV, we included measurements of WM T1w/T2 $\mathrm{w}$ as a per-vertex regressor in our model to assess for potential cortical-specific effects (see below). Therefore, we sampled WM $\mathrm{T} 1 \mathrm{w} / \mathrm{T} 2 \mathrm{w}$ values at a $1.0 \mathrm{~mm}$ distance from the WM/GM boundary into the $\mathrm{WM}$, creating WM T1w/T2w surfaces.

DTI has emerged as a widely applied and validated method of assessing brain microstructure (Concha et al., 2006). DTI-derived indices have been linked to myelin (Song et al., 2005), but likely primarily reflect other microstructural properties such as axon fiber diameter and density (Beaulieu, 2002). Therefore, even if not being predominantly a measure of myelin, DTI is a viable way of measuring microstructural changes over the lifespan (Lebel et al., 2012). Although challenges exist in estimating diffusivity in the cortex due to partial-volume effects (Koo et al., 2009), it has been successfully applied to detect GM alterations in, for example, aging (Abe et al., 2008). Therefore, we included DTI measurements to allow for comparisons of the new T1w/T2w ratio method with a previously established method of microstructure assessment.

DTI image analyses and tensor calculations were done using FSL (Smith et al., 2004; Woolrich et al., 2009). Each volume was affine registered to the T2-weighted $\mathrm{b}=0$ volume using FLIRT (Jenkinson and Smith, 2001) correcting for motion between scans and residual eddycurrent distortions. After removal of nonbrain tissue (Smith, 2002) eigenvector and eigenvalue maps were computed. We chose $\mathrm{MD}$, the mean of the eigenvalues $[(\lambda 1+\lambda 2+k \lambda) / 3]$, as the measure of interest because GM has been shown have low values of anisotropy (Pierpaoli et al., 1996), thus potentially making other sensitive and commonly used indices such as fractional anisotropy and radial diffusivity (Grydeland et al., 2010) less informative. The first T2-weighted $b=0$ volume was registered to the unresampled $\mathrm{T} 1 \mathrm{w}$ volume in the same way as the $\mathrm{T} 2 \mathrm{w}$ image, and the resulting transform was then used to register the MD volume to the T1w volume. The MD values were subsequently sampled in an identical manner to the T1w/T2w values.

All individual surfaces (cortical T1w/T2w, WM T1w/T2w, MD, and thickness maps) were mapped to a common surface using a nonrigid, high-dimensional spherical averaging method to align cortical folding patterns (Fischl et al., 1999a; Fischl et al., 1999b), smoothed with a circularly symmetric Gaussian kernel across the surface using a full width at half maximum of $12 \mathrm{~mm}$, and fed to statistical analyses. To perform curve-fitting analyses for visualization of the estimated lifespan trajectories, we divided the surface into 33 gyral-based areas in each hemisphere (Fischl et al., 2004b; Desikan et al., 2006) and averaged the measures of interest within selected cortical parcellations.

Experimental task. We administered a modified version of the Eriksen flanker task (Eriksen and Eriksen, 1974), similar to the task used by Debener et al. (2005), described in detail previously (Westlye et al., 2009a). The procedure and preprocessing steps are identical to, and previously described in, Fjell et al. (2011) and Tamnes et al. (2012) for the adult and young subsample, respectively. Briefly, horizontal arrows (length $=1^{\circ}$ ) pointing either to the left or the right were displayed centrally on a computer screen in a vertical stack $2.5^{\circ}$ high. Subjects were instructed to respond as accurately and quickly as possible by pressing one button if the target was pointing to the left and another button if the target was pointing to the right. Each trial consisted of a central fixation cross presented for a random interval ranging between 1200 and 1800 $\mathrm{ms}$, followed by the presentation of four "flanker" arrows for $80 \mathrm{~ms}$ before the target arrow appeared in the middle of the stack of flanker arrows for 30 and $60 \mathrm{~ms}$ for the adult and young subsample, respectively.
The flanker arrows were presented before the target to increase prepotent responding and to make the task more difficult. A training session of 20 and 24 trials for the adult and young subsample, respectively, was administered to familiarize the participant with the task.

Responses were obtained on a PST Serial Response Box and the experimental procedures and responses were collected using E-prime software (Psychological Software Tools). The task included 416 trials with a short break halfway and there were two experimental task conditions, congruent and incongruent, with 208 trials each. In the congruent condition, all arrows pointed in the same direction. In the incongruent condition, the middle arrow pointed in the direction opposite of that of the flanker arrows. The probability of an incongruent trial was $50 \%$ in a randomized fashion. Because both Fjell et al. (2011) and Tamnes et al. (2012) found robust effects in both conditions, we here limited our analyses to values based on the congruent trials.

Based on the mean RT for the first 20 consecutive trials, an individually adjusted RT criterion was set $(10 \%$ and $15 \%$ above mean RT of the 20 initial trials for the adult and the young subsample, respectively). After every subsequent third trial with either RT exceeding this criterion or with response omission, a message occurred on screen for $1 \mathrm{~s}$ instructing the participant to respond faster. The rational for using this procedure was to increase the participants' motivation for rapid responses and to enhance their attentional investments in the task. We expected that this would lead to reduced variability due to random attentional drifts and leave us with a measure of variability more closely related to task-focused CNS function. Therefore, IIV in this task may be more related to the ability to respond in a constant and speedy manner rather than naturally occurring trial-to-trial variability.

For the statistical analyses, we excluded the first 10 trials and the 10 trials with the fastest and slowest RTs for each subject because it is difficult to decide whether extreme responses represent variations of the real cognitive processes under study or if they result from random noise due to factors such as the participant missing the button, having a single lapse of attention during the course of a long speeded task, etc. Although such instances of attention lapses likely reflect a phenomenon of interest, the difficulty in discerning it from missed button press and other random noise constitutes a challenge. Therefore, a simple way of reducing the possibility that noise contaminate the data without biasing the results in either direction (although at a cost of leaving out potentially interesting data) is to exclude the extreme ends of the RT distribution for all participants. The approach does not, however, completely preclude the presence of extreme values beyond the 10 fastest and 10 slowest RTs, although if present, these are likely of a limited number with negligible impact on the data. As in our previous studies (Fjell et al., 2011; Tamnes et al., 2012), for the resulting trials, we operationalized IIV by calculating the SD of the RT (sdRT) as the measure of interest; median RT (mRT) was included as a covariate in all analyses to control for effects of reaction time because a relationship between sdRT and $\mathrm{mRT}$ is expected (for a discussion related to the quantification of IIV, see MacDonald et al., 2009). Median RT was preferred to mean RT because RT generally does not follow strict normal distribution but has a thicker tail of slow compared with fast values. In the present dataset, the correlation between the median and the mean RT was 0.995 and 0.960 in the adult and the young subsample, respectively.

Statistics. For the entire sample, we applied general linear models (GLMs) to test for expected (Westlye et al., 2010b) quadratic effects of age $\left(\mathrm{age}^{2}\right)$ on the cortical T1w/T2w ratio and MD maps at each vertex with terms for the linear effects of age and sex as global covariates. For the T1w/T2w ratio analyses, we first estimated the effect of difference in T2w matrix across the whole sample to minimize potential confounds with age and the subsample analyses were performed on the resulting residuals. Cortical thickness was included as a per-vertex regressor in all GLMs. To estimate age trajectories without any assumption about the form of the curve, we fitted a nonparametric local smoothing model, the smoothing spline, implemented in MATLAB (MathWorks), to the mean values of representative regions of interest (ROI) across the mantle. We calculated $z$-scores from the residuals after modeling the effect of T2w matrix type and plotted the mean values across hemispheres per ROI. We have shown previously that the smoothing spline approach yields less biased solutions than the more commonly used higher order polynomial functions (Fjell et al., 2010). We used 


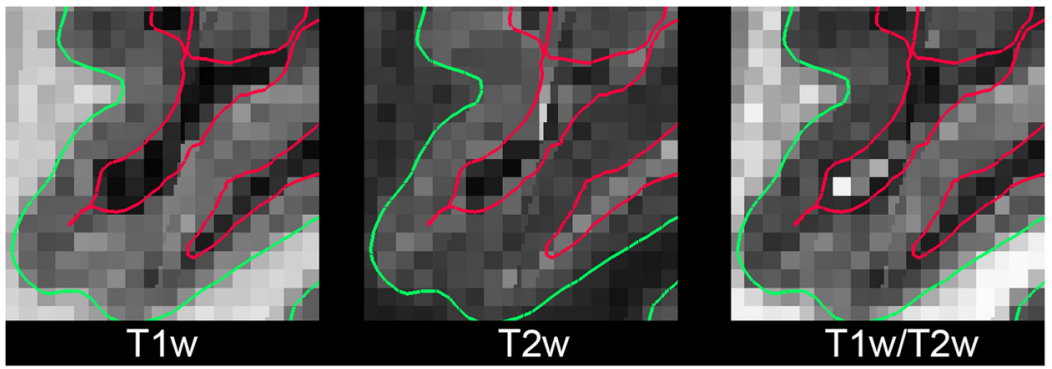

Figure 1. T1 $\mathrm{w}, \mathrm{T} 2 \mathrm{w}$, and $\mathrm{T} 1 \mathrm{w} / \mathrm{T} 2 \mathrm{w}$ volumes. Shown is a section of a $\mathrm{T} 1 \mathrm{w}, \mathrm{T} 2 \mathrm{w}$, and $\mathrm{T} 1 \mathrm{w} / \mathrm{T} 2 \mathrm{w}$ volume, respectively, illustrating the highly myelinated transverse temporal part of the superior temporal lobe (the middle gyrus, denoted with an asterisk in the T1w) evidencing lighter, darker, and lighter intensity, respectively, than the surrounding cortical tissue. The green surface denotes the sampling distance of 0.2 and the red line represents the GM/CSF boundary.

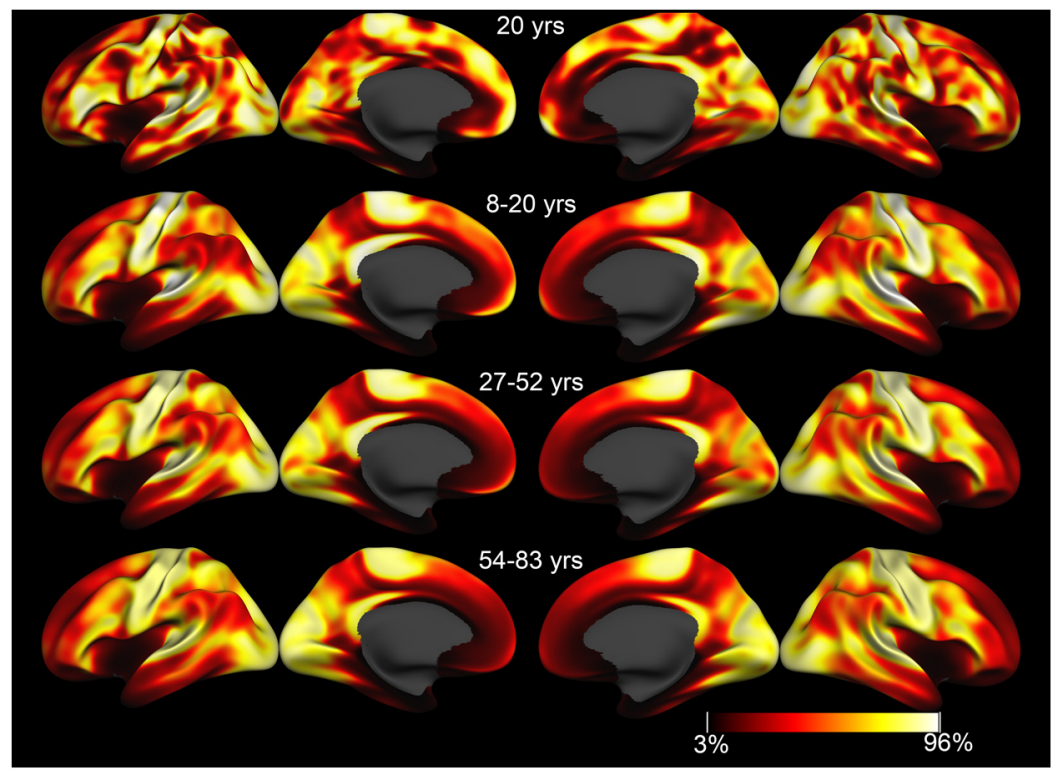

Figure 2. T1w/T2w ratio surface maps. Shown are $T 1 w / T 2 w$ ratio surface maps from a female 20 years of age overlaid on a semi-inflated surface. Average T1w/T2w ratio surface of maps of the young subsample ( $n=85$, age 8.3-19.7 years), middle-aged participants ( $n=85$, age 27.4 -51.7 years), and the oldest participants ( $n=85$, age $58.4-83.1$ years). T1w/T2w ratio values below the third percentile and above the 96th percentile, calculated across participants, are sat to saturation (dark and light, respectively).

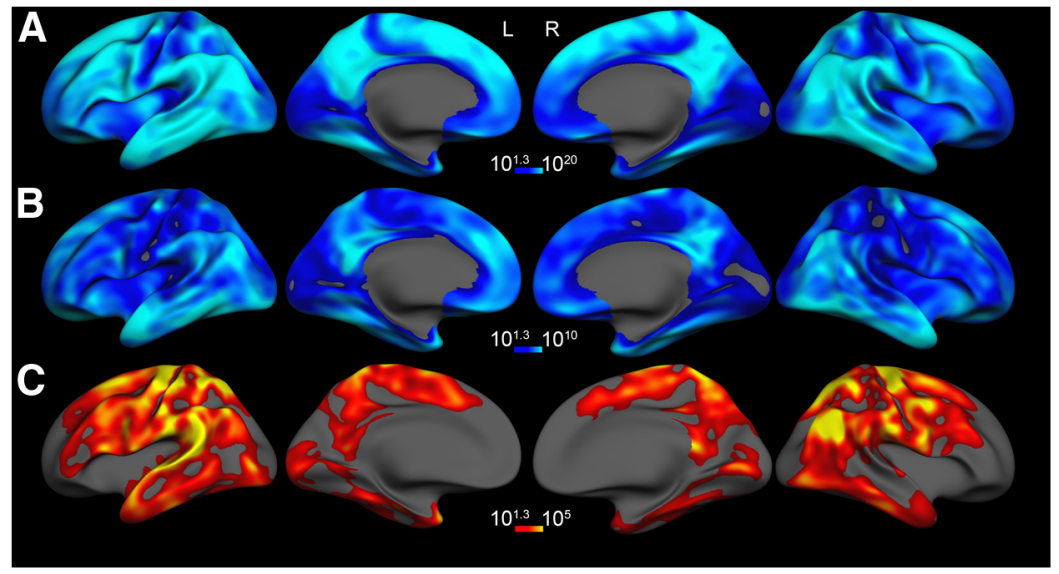

Figure 3. T1w/T2w myelin ratio and age. $p$-value maps are overlaid on semi-inflated brains showing the relationship between $\mathrm{T} 1 \mathrm{w} / \mathrm{T} 2 \mathrm{w}$ myelin ratio and the quadratic effects of age in all subjects (age $8-83$ years; $\boldsymbol{A}$ ), the quadratic effects of age in the adult subsample (age $20-83$ years; $\boldsymbol{B}$ ), and the linear effects of age in the young subsample (age $8-19$ years; $C$ ), respectively. The effects are corrected for multiple comparisons, but actual $p$-values are shown. See Table 2 for clusterwise $p$-values. an algorithm that optimizes smoothing level based on a version of Bayesian Information Criterion, which provides a way of obviating the need for arbitrarily chosen smoothing levels. The following distributed ROIs were chosen to cover distributed parts of the cortical mantle and to allow comparison with Westlye et al. (2010b): superior frontal, rostral middle frontal, paracentral, superior parietal, inferior temporal, isthmus cingulate, parahippocampal, pericalcarine, and insula. Similarly, we also performed the smoothing spline fitting at each vertex, saved age at the peak (highest T1w/T2w ratio value) on the resulting curve, and displayed the results as surface maps to give an even more detailed picture of the transition between development and aging. To probe the relationship between intracortical myelin and IIV, we tested linear effects of sdRT on T1w/T2w ratio and MD values with GLMs while regressing out $\mathrm{mRT}$, sex, and age, and thickness per-vertex. We ran GLMs to explicitly test whether the relationship between sdRT and T1w/T2w ratio and MD, respectively, changed with age. The age $X$ sdRT interaction term was included in the analyses, using sex, age, mRT, sdRT, and thickness pervertex as covariates. We repeated the IIV analyses including WM T1w/T2 $\mathrm{w}$ as per-vertex regressor to assess for potential cortical-specific effects. For all surface analyses, the data were tested against an empirical null distribution of maximum cluster size across 10,000 iterations using Z Monte Carlo simulations as implemented in FreeSurfer (Hagler et al., 2006) synthesized with a clusterforming threshold of $p<0.05$ (two-sided), yielding clusters corrected for multiple comparisons across the surfaces with corresponding clusterwise $p$-values. To illustrate the individual data points and to provide a general measure of effect size, we extracted values from significant cluster vertices and plotted against sdRT. These correlation analyses were restricted to vertices for which the values were already to be significantly related to IIV and thus must not be regarded as part of the hypothesis testing, but rather as a suitable way of estimating effect sizes. Finally, we tested the robustness of the behavioral associations and the potential effects of general intellectual functioning by entering the mean values in a regression, calculating studentized deleted residuals, excluding cases exceeding \pm 2.5 (which was considered more stringent than a Bonferroni-corrected cutoff value) and rerunning the regression including FIQ as a covariate (together with age, sex, and cortical thickness). Specifically, we tested whether removing potential outliers and including FIQ would remove the statistical relationship between microstructure and IIV.

\section{Results}

Intracortical $\mathrm{T} 1 \mathrm{w} / \mathrm{T} 2 \mathrm{w}$ ratio myelin and age

Figure 1 shows excerpt from T1w, T2w, and $\mathrm{T} 1 \mathrm{w} / \mathrm{T} 2 \mathrm{w}$ volumes from a female 20 years of age; Figure 2 shows T1w/T2w ratio surface maps for the same female and 3 -group average maps of 85 subjects each, $8-20,27-52$, and $58-83$ years of age, respectively. 
Figure $3 A$ displays $p$-value maps of intracortical T1w/T2w as a function of age ${ }^{2}$ in each vertex across all subjects, with age and sex as global covariates and cortical thickness as a per-vertex regressor. Widespread negative quadratic effects, indicating an inverted $\mathrm{U}$-shaped relationship between $\mathrm{T} 1 \mathrm{w} / \mathrm{T} 2 \mathrm{w}$ ratio and age, were found, covering $\sim 91 \%$ the vertices in each hemisphere (for details, see Table 2). Specifically, the strongest effects were observed in frontal, parietal, and temporal association areas, whereas primary sensory areas showed weaker effects. We repeated the quadratic analysis of age in only the adult subsample and tested for the linear effects of age in the young subsample. In the adults (Fig. $3 B$ ), the quadratic effects were similar, but naturally statistically weaker, compared with the whole sample. In the youngest subsample (Fig. 3C), widespread linear effects comprising $81 \%$ and $74 \%$ of the vertices in the left and right hemisphere, respectively, were found, indicating increasing T1w/T2w ratio with age. Effects were prominent particularly in posterior frontal, parietal, and temporal cortices; weaker or no effects were found in parts of anterior frontal, insular, and lateral occipital cortices.

Figure 4 illustrates the lifespan T1w/T2 $\mathrm{w}$ ratio trajectories in the selected ROIs showing the fitted smoothing spline curve. The majority of regions showed an inverted U-shaped T1w/T2w ratio trajectory across life: a steep increase until the end of the $30 \mathrm{~s}$, followed by a relatively stable period, before a decrease from the end of the 50s. Deviating somewhat from this pattern, the parahippocampal and paracentral cortex showed a more protracted increase and a less steep decline around the sixth decade, whereas the pericalcarine cortex trajectory did not evidence any decrease, instead increasing quite linearly through the whole age range. Figure 5 depicts surface maps showing the age of the transition between development and aging-related decline in T1w/T2w ratio after fitting the same smoothing spline at each vertex. Superior frontal, inferior parietal and temporal, and posterior cingulate cortices demonstrated the earliest signs of transition, whereas heavily myelinated primary sensory areas did not show decline.

Figure 6 shows WM T1w/T2w ratio age trajectories in the same selected ROIs as for GM T1w/T2w. In general, the curves show a less protracted development than the GM curves, but a similar though somewhat more pronounced decline from the late 50s. The mean correlation between WM and GM T1w/T2w across vertices was similar in the left and right hemisphere: 0.61 for adults and 0.67 for the young. In the adults, there was a trend for an increase in the correlations with age: 0.58 in adults below adult median age ( 52 years), and 0.70 above ( $p$-value of difference between correlations $=0.06$, one-tailed).

\section{Intracortical $\mathrm{MD}$ and age}

Figure $7 A$ depicts $p$-value maps of intracortical DTI-derived MD as function of age ${ }^{2}$ in each vertex across all subjects, with age and sex as global regressors and cortical thickness as a per-vertex regressor. Positive relationships indicating a U-shaped trajectory across age was found in $83 \%$ of the vertices in the left hemisphere and $86 \%$ in the right (for details, see Table 2). The strongest effects were seen in middle and superior frontal, cingulate, supramarginal, and inferior parietal cortices, generally bilateral but with slightly more pronounced right lateral prefrontal effects. Again, we repeated the analyses in the adult and young subsample separately: widespread quadratic effects $(74 \%$ and $78 \%$ of the vertices in the left and right hemisphere, respectively) of age on MD were again found in the adults (Fig. $7 B$ ). The positive effects, reflecting a $\mathrm{U}$-shaped relationship with age, were particularly strong in superior frontal, cingulate, precuneal, supramarginal, parietal, insular, and lateral occipital cortices. Weaker or no ef-
Table 2. Significant cluster details

\begin{tabular}{|c|c|c|c|}
\hline Region Max Vtx (hemi) & $\% \mathrm{Vtx}$ & Max $p$-value & CWP \\
\hline \multicolumn{4}{|l|}{$\mathrm{T} 1 \mathrm{w} / \mathrm{T} 2 \mathrm{w}$} \\
\hline \multicolumn{4}{|l|}{ All - age ${ }^{2}$} \\
\hline Inferior parietal (lh) & 90.7 & -30.8 & 0.0001 \\
\hline Inferior parietal (rh) & 90.6 & -32.6 & 0.0001 \\
\hline \multicolumn{4}{|l|}{ Adults - age ${ }^{2}$} \\
\hline Superior frontal (lh) & 89.1 & -13.8 & 0.0001 \\
\hline Superior frontal (rh) & 88.5 & -12.8 & 0.0001 \\
\hline \multicolumn{4}{|l|}{ Young - age } \\
\hline Postcentral (lh) & 81.1 & 13.3 & 0.0001 \\
\hline Precentral (rh) & 73.8 & 13.1 & 0.0001 \\
\hline \multicolumn{4}{|l|}{ Adults - IIV } \\
\hline Lingual (Ih) & 2.5 & -3.3 & 0.0028 \\
\hline Superior temporal (rh) & 5.7 & -4.5 & 0.0001 \\
\hline Insula & 2.2 & -3.9 & 0.0455 \\
\hline Supramarginal & 4.2 & -3.1 & 0.0003 \\
\hline Postentral & 2.8 & -3.0 & 0.0113 \\
\hline \multicolumn{4}{|l|}{ Young - IIV } \\
\hline Lateral occipital (lh) & 12.5 & 4.1 & 0.0001 \\
\hline Postcentral & 4.9 & 2.9 & 0.0001 \\
\hline Superior parietal (rh) & 11.2 & 4.2 & 0.0001 \\
\hline Postcentral & 2.5 & 3.4 & 0.0368 \\
\hline \multicolumn{4}{|l|}{ Adults - IIV WM cov } \\
\hline Superior temporal (rh) & 1.8 & -4.0 & 0.0081 \\
\hline \multicolumn{4}{|l|}{ Young - IIV WM coV } \\
\hline Superior parietal (lh) & 14.7 & 4.0 & 0.0001 \\
\hline Supramarginal & 5.2 & 3.0 & 0.0001 \\
\hline Precentral & 1.7 & 3.0 & 0.0327 \\
\hline Paracentral & 2.0 & 3.0 & 0.0153 \\
\hline Superior parietal (rh) & 12.0 & 3.8 & 0.0001 \\
\hline Postcentral & 2.5 & 3.3 & 0.0025 \\
\hline Insula & 1.7 & 3.2 & 0.0248 \\
\hline \multicolumn{4}{|l|}{ Adults - IIV $\times$ age } \\
\hline Middle temporal (lh) & 20.6 & -4.5 & 0.0001 \\
\hline Supramarginal & 4.1 & -4.1 & 0.0004 \\
\hline Middle temporal (rh) & 24.4 & -5.4 & 0.0001 \\
\hline \multicolumn{4}{|l|}{ MD } \\
\hline \multicolumn{4}{|l|}{ All - age ${ }^{2}$} \\
\hline Superior frontal (lh) & 83.2 & 25.4 & 0.0001 \\
\hline Lateral orbitofrontal (rh) & 85.8 & 33.4 & 0.0001 \\
\hline \multicolumn{4}{|l|}{ Adults - ge $^{2}$} \\
\hline Superior frontal (lh) & 72.9 & 19.2 & 0.0001 \\
\hline Supramarginal (rh) & 78.2 & 27.4 & 0.0001 \\
\hline \multicolumn{4}{|l|}{ Young - age } \\
\hline Precentral (lh) & 48.2 & -10.7 & 0.0001 \\
\hline Lingual & 0.9 & 6.2 & 0.0437 \\
\hline Precentral (rh) & 41.7 & -10.5 & 0.0001 \\
\hline \multicolumn{4}{|l|}{ Adults - IIV } \\
\hline Pericalcarine (lh) & 2.9 & 3.8 & 0.0001 \\
\hline Pars triangularis (rh) & 3.6 & 4.6 & 0.0001 \\
\hline Lingual & 1.3 & 3.1 & 0.0024 \\
\hline Young - IIV & & & \\
\hline Pericalcarine (lh) & 1.1 & -5.4 & 0.0146 \\
\hline Precentral & 4.8 & 4.4 & 0.0001 \\
\hline Superior frontal (rh) & 1.7 & 3.6 & 0.0342 \\
\hline Precentral & 2.3 & 3.1 & 0.0030 \\
\hline Pericalcarine & 2.0 & -2.9 & 0.0040 \\
\hline Adults - IIV $\times$ age & & & \\
\hline Posterior cingulate (Ih) & 4.3 & 3.9 & 0.0001 \\
\hline Superior temporal & 1.5 & 3.3 & 0.0341 \\
\hline Rostralmiddle frontal (rh) & 4.3 & 4.9 & 0.0001 \\
\hline Entorhinal & 1.5 & 4.9 & 0.0088 \\
\hline Precuneus & 7.8 & 4.4 & 0.0001 \\
\hline Inferior parietal & 12.5 & 4.1 & 0.0001 \\
\hline Precentral & 1.4 & 3.1 & 0.0244 \\
\hline Lingual & 1.8 & 2.4 & 0.0007 \\
\hline
\end{tabular}

Region Max Vtx, region of maximum $p$-value vertex; hemi, hemisphere; $\%$ Vtx, percent of total vertices; Max $p$-value, maximum $p$-value $\left(10^{p}\right)$ in cluster; (WP, clusterwise $p$-value (the $p$-value of the cluster); lh, left hemisphere; rh, right hemisphere. WM cov, WM T1w/T2w included as a covariate. 

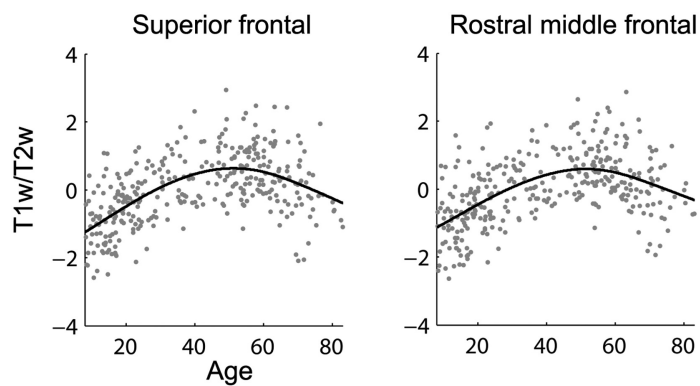

Superior parietal

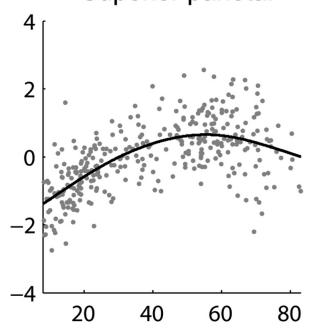

Parahippocampal

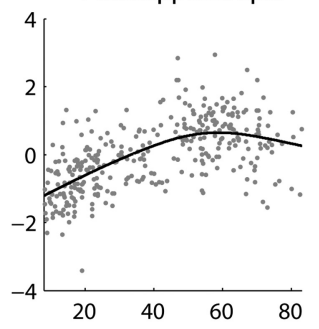

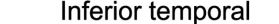

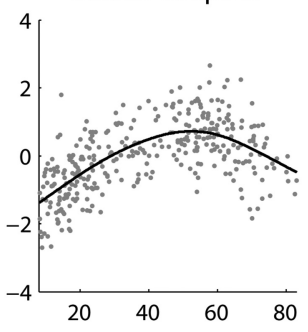

Pericalcarine

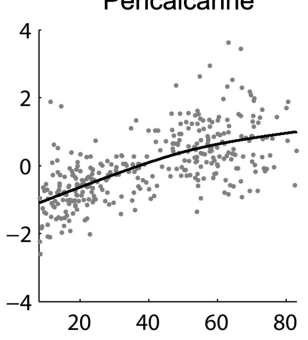

Paracentral

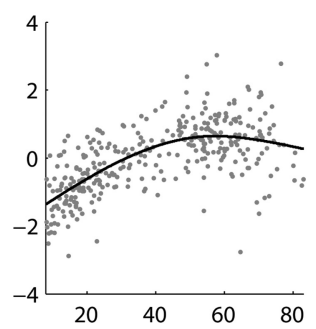

Isthmus cingulate

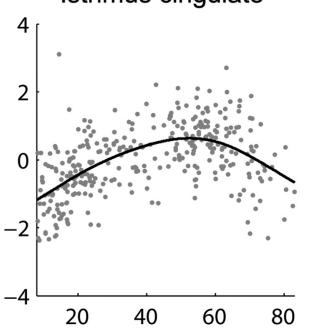

Insula

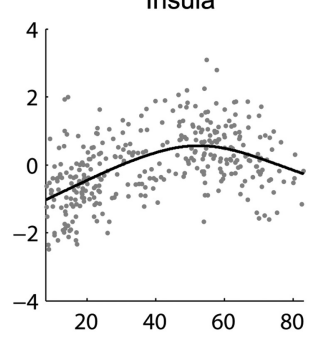

Figure 4. Lifespan T1w/T2w ratio trajectories in selected cortical ROIs. Values are standardized residual after regression of the T2w matrix; please see Materials and Methods for details. Age values are in years.

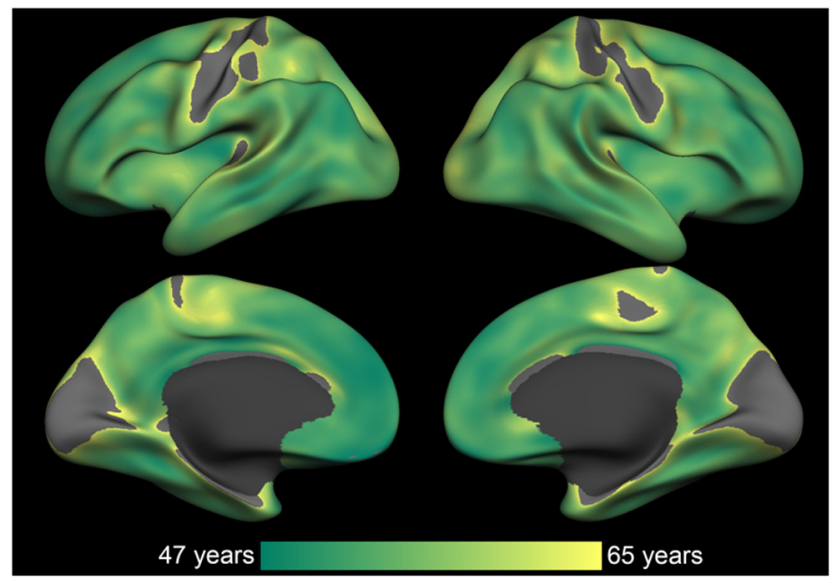

Figure 5. Development-aging transition. Surface maps show the age of the transition between development and aging. Vertexes not evidencing a peak before age 65 were set to a light gray color. The noncortical medial wall is set to a darker gray.

fects were apparent in temporal, around the central sulcus, and frontal pole cortices. In the young subsample (Fig. 7C), we observed negative linear effects in $48 \%$ and $42 \%$ of the vertices in the left and right hemisphere, respectively, particularly in precentral, superior temporal, superior frontal, and rostral middle frontal cortices, as well as medially in cingulate and precuneus cortices. A small cluster ( $1 \%$ of the vertices) showing marginally significant positive effects was also found peaking in the left lingual cortex, extending into pericalcarine cortex.

Figure 8 shows the lifespan mean MD trajectories in the same ROIs shown in Figures 4 and 6 . The majority of regions show a U-shaped trajectory across life, the opposite of the T1w/T2w ratio pattern: a decrease in MD during the first decades of life, followed by a stable period, before an increase in MD with age starts around the sixth decade. Slight exceptions to this general pattern were seen in the paracentral, superior parietal, and pericalcarine cortices, none showing a decrease during the first two decades of life. The parahippocampal cortex, as for the T1w/T2w ratio, did not show any plateau, but an increase already from the early 20 s.

\section{Intracortical $\mathrm{T} 1 \mathrm{w} / \mathrm{T} 2 \mathrm{w}$ ratio myelin and cognition}

There were no differences across sex in sdRT (Mann-Whitney $U$ test, adults: $z=-1.17$, $p=0.200$; young, $z=0.90, p=0.367$ ) or mRT (adults: $z=-0.44, p=0.662$ ); young: $z=0.923, p=0.356)$. In the adults, age correlated positively with both $\operatorname{sdRT}(r=0.36$, $\left.p<10^{-8}\right)$ and $\mathrm{mRT}\left(r=0.65, p<10^{-31}\right)$, but sdRT was not significantly related to age when controlling for $\mathrm{mRT}$ (estimate = $0.059, \mathrm{SE}=0.042, t$-stat $=1.392, p$-value $=$ $0.165)$. In the young, age correlated negatively with $\operatorname{sdRT}\left(r=-0.64, p<10^{-10}\right)$, even when controlling for $\mathrm{mRT}$ (estimate $=$ $-0.047, p$-value $=0.008)$ and with $\mathrm{mRT}$ $\left(r=-0.62, p<10^{-9}\right)$.

To assess functional correlates of intracortical myelin, we performed similar analyses as in our previous studies, assessing the relationship between IIV and WM integrity separately for the adult and young subsample (Fjell et al., 2011; Tamnes et al., 2012). The results are presented in Figures 9 and 10 and in Table 2 . In the adults, 1 cluster in the left hemisphere covering $2.5 \%$ of the vertices with peak in the lingual cortex extending medially into the temporal cortex showed a negative relationship between sdRT and T1w/T2w ratio (Fig. 9A). In the right hemisphere, four clusters covering $14.5 \%$ of the surface with peak values in superior temporal, insula, supramarginal, and postcentral cortices, respectively, showed a similar negative relationship. Therefore, higher variability in task performance was related to a lower T1w/ $\mathrm{T} 2 \mathrm{w}$ ratio, indicating reduced intracortical myelin, particularly in the right hemisphere. The relationships were of modest strength, with a mean Pearson product-moment correlation of -0.21 in both hemispheres. In the young subsample (Fig. 9B), two clusters covering $17.4 \%$ of the vertices peaking in the left lateral occipital and postcentral cortices and two right hemisphere clusters ( $13.1 \%$ of the vertices) with peaks in superior parietal and postcentral cortices showed a positive relationship between the T1w/ $\mathrm{T} 2 \mathrm{w}$ ratio and sdRT. Therefore, contrary to what was expected, increased variability in task performance was related to higher $\mathrm{T} 1 \mathrm{w} / \mathrm{T} 2 \mathrm{w}$ ratio in these posterior regions. Correlations across clusters were 0.35 and 0.36 in the left and right hemispheres, respectively.

To investigate whether the relation between T1w/T2w and sdRT changed as a function of age, we added the interaction term age $\times$ sdRT to the previous linear model including age and sex as 
global covariates and thickness as a pervertex covariate. In the adults, two left hemisphere clusters comprising $25 \%$ of the vertices peaking in middle temporal and supramarginal cortices showed significant negative age interactions (Fig. 9C). This result indicates a stronger negative relationship between $\mathrm{T} 1 \mathrm{w} / \mathrm{T} 2 \mathrm{w}$ and sdRT with increased age, as can be seen in the scatter plots in Figure $9 C$, in which the adult group has been divided based on the median age (52 years). One right hemisphere cluster spanning $24 \%$ of the vertices with maximum values in middle temporal cortex showed a similar age interaction. The mean correlations in the left and right hemisphere for the elderly were -0.09 and -0.12 , respectively, and 0.06 and 0.04 in the young adults $(<52$ years), respectively. No interactions were found in the young subsample $(<20$ years).

All IIV-T1w/T2w ratio associations remained highly significant and correlations were generally unchanged when rerunning the regression after excluding studentized deleted residuals exceeding \pm 2.5 . In the same model, FIQ did not yield a unique statistical contribution on T1w/T2w ratio (though showing a trend toward significance in one instance). Specifically, the IIV-T1w/T2w ratio correlations in the adults were similar in both the left (Pearson's $r$ from -0.21 to $-0.23 ; 6$ cases exceeding the threshold of 2.5) and the right hemisphere (from -0.21 to $-0.20,7$ cases exceeding the threshold). For the age-IIV interaction, the IIV-T1w/ $\mathrm{T} 2 \mathrm{w}$ ratio correlation in the young adults was slightly reduced in both the left (from 0.06 to $0.03,8$ cases exceeding the threshold) and the right hemisphere (0.04 to $-0.02,7$ cases exceeding the threshold). For the oldest part of the adult subsample, there was a minor increase in the left hemisphere associations (from -0.09 to -0.11 ) and a large increase in right hemisphere associations $(-0.12$ to -0.21$)$. For the youngest subsample, the left hemisphere IIV correlation was identical ( 0.35 in both instances), whereas the association in the right was clearly reduced (from 0.36 to 0.27 ).

When including WM T1w/T2w as a per-vertex regressor to assess the specificity of the GM T1w/T2wIIV association, the effects were reduced to a cluster of 2880 vertices $(1.8 \%)$ with peak in the superior temporal cortex in the adults. No interaction effect of age and IIV on GM T1w/T2w remained when controlling for WM T1w/T2w. For the youngest subsample, the inclusion of WM T1w/T2w did not alter the results (four clusters in the left hemisphere covering $23.6 \%$ of the vertices with peaks in superior parietal, supramarginal, and preand paracentral cortices, respectively, and $16.3 \%$ of the vertices in
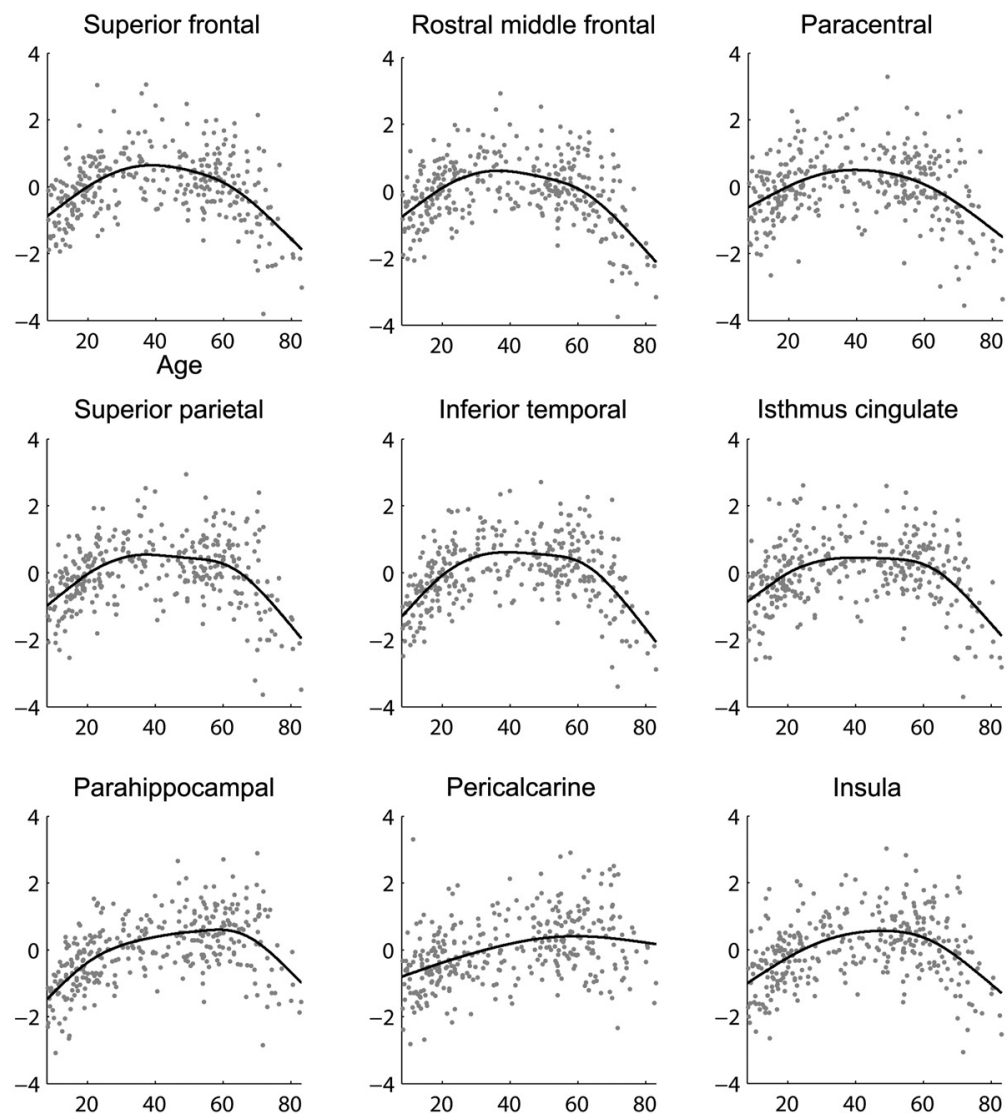

Figure 6. Lifespan WM T1w/T2w ratio trajectories in the subjacent WM to the selected cortical R0ls. Values are standardized residual after regression of the T2w matrix; please see Materials and Methods for details. Age values are in years.

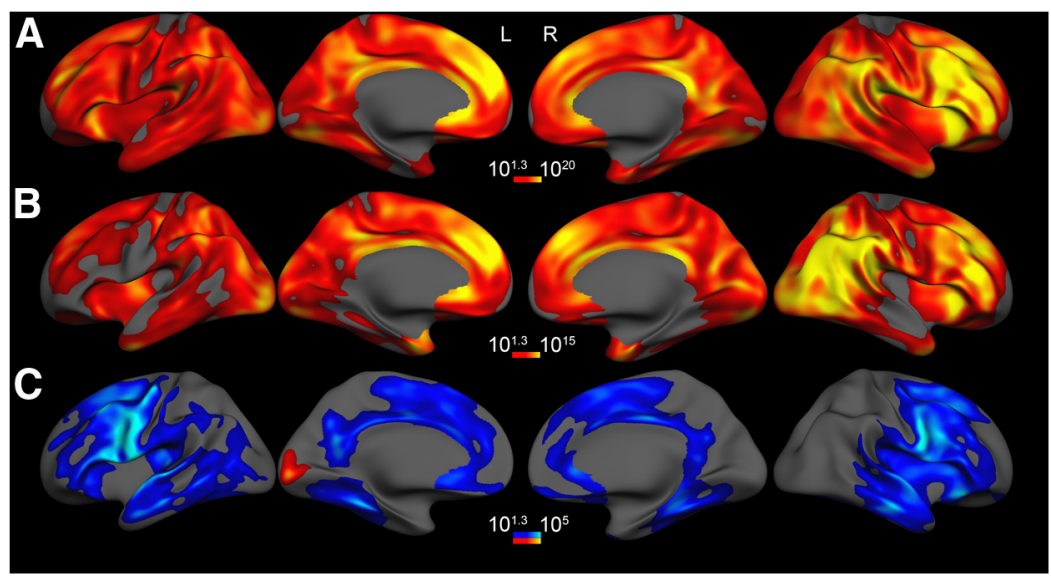

Figure 7. DTI-derived MD and age. $p$-value maps showing the relationship between MD and the quadratic effects of age in all subjects (age 8 - 83 years; $\boldsymbol{A}$ ), the quadratic effects of age in the adult subsample (age $20-83$ years; $\boldsymbol{B}$ ), and the linear effects of age in the young subsample (age $8-19$ years; $\boldsymbol{C}$, respectively. The effects are corrected for multiple comparisons, but actual $p$-values are shown. See Table 2 for clusterwise $p$-values.

the right hemisphere peaking in superior parietal, postcentral, and insula showed a positive relationship between sdRT and $\mathrm{T} 1 \mathrm{w} / \mathrm{T} 2 \mathrm{w}$ ratio).

We repeated the above analyses assessing functional correlates of intracortical myelin, now testing for a relationship between IIV and intracortical MD separately for the adult and young subsample (Fig. 10A). One left hemisphere cluster covering 3\% of the vertices peaking in the pericalcarine cortex and extending dorsally into precuneus and posterior cingulate cortices showed a 

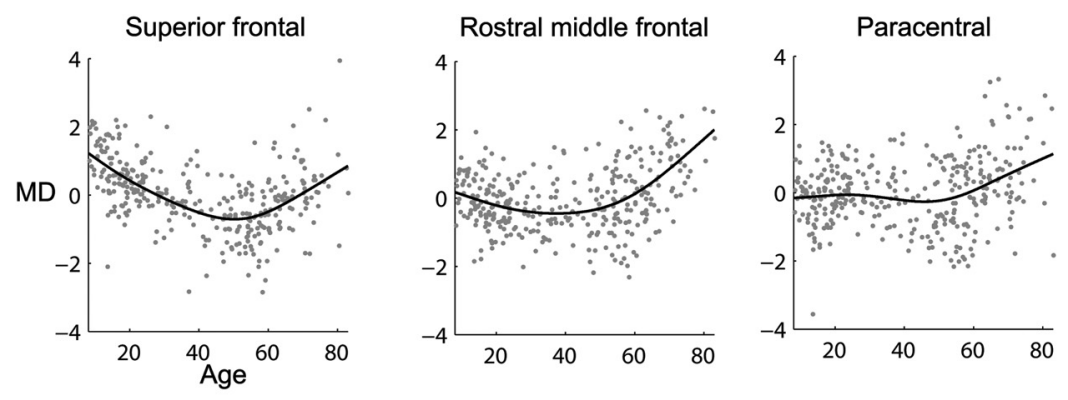

Inferior temporal
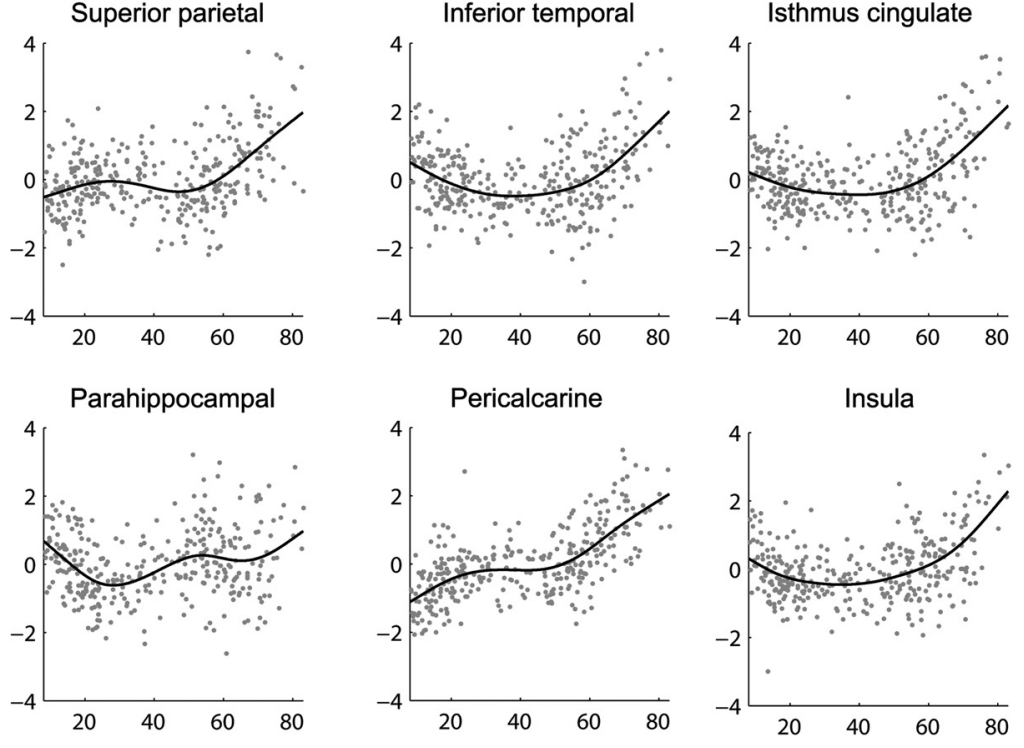

Figure 8. Lifespan MD trajectories in selected cortical ROIs. MD values are standardized z-scores. Age values are in years.

positive relationship between sdRT and MD in the adults. In the right hemisphere, 2 clusters with peaks in pars triangularis and lingual cortices, respectively, covering a total of $5 \%$ of the surface showed a similar positive relationship. Therefore, increased variability in task performance was related to higher MD. Again, the relationships were relatively modest, with mean correlations of 0.21 and 0.26 in the left and right significant clusters, respectively. In the young subsample (Fig. 10B), 1 cluster covering $5 \%$ of the vertices with peak value in the left precentral cortex extending anteriorly, showed a positive relationship between MD and sdRT, as previously observed in the adult subsample. A similar cluster was found in the right hemisphere in addition to a superior frontal cluster (each $2 \%$ of all vertices). Two clusters peaking in the left and right pericalcarine cortex (1\% of the vertices, respectively) showed a negative relationship, indicating that increased variability in task performance was related to lower MD in this occipital region. In addition, a right mainly lateral occipital cluster, but with peak value in posterior middle temporal cortex, also showed a similar negative relationship (1\% of the vertices). The relationships were stronger, mean positive correlations were 0.43 and 0.42 , and mean negative correlations were -0.38 and -0.32 , for left and right hemispheres, respectively.

To investigate whether the relation between MD and sdRT changes as a function of age, we added the interaction term age $X$ sdRT to the previous linear model including age and sex as global variables and thickness as a per-vertex variable. As seen in Figure $10 C$, in the adults, 1 left hemisphere cluster of 7035 vertices $(4.3 \%)$ peaking in the posterior cingulate cortex but extending anteriorly through the entire cingulate cortex and medial superior frontal cortices showed significant positive age interactions, indicating a stronger relationship between $\mathrm{MD}$ and IIV with increasing age (mean $r=0.06$ in the youngest half of the sample and 0.14 in the oldest half). A similar pattern was seen in the right hemisphere, however, the effects were much more widespread, with six clusters covering 48,031 vertices $(29.3 \%)$ peaking in the rostral middle frontal, precentral, precuneus, inferior parietal, entorhinal, and lingual cortices. Again, the positive relationship between MD and IIV manifests itself mainly in the oldest group, as can be seen in the scatter plots, in which the adult group has been divided by the median age into two groups; mean correlations were 0.02 and 0.12 in the oldest half for the left and right hemispheres, respectively, and -0.05 and -0.10 in the youngest half of the adult sample $(<52$ years).

As for the T1w/T2w-IIV analyses, we reran the regression analyses after excluding studentized deleted residuals exceeding \pm 2.5 , including FIQ as a covariate to assess specificity. Again, all MD and IIV associations remained highly significant and FIQ did not yield a unique statistical contribution on MD. The IIV-MD associations generally did not change. For the adults, the IIV-MD association increased slightly in left (Pearson's $r$ from 0.21 to 0.26 ; 6 cases exceeding the threshold of 2.5) and right hemispheres (from 0.26 to 0.31; 4 cases exceeding the threshold). The age-IIV interaction correlations with MD were reduced for the youngest adults in the left (from -0.05 to $-0.02 ; 3$ cases exceeding the threshold) and right hemispheres (from -0.10 to $-0.05 ; 5$ cases exceeding the threshold). For the oldest adults, the left hemisphere correlations increased slightly (from 0.02 to 0.05 ), and a slight decrease was found in the right hemisphere (from 0.12 to 0.10 ). In the youngest subsample, the positive correlations were slightly increased in the left hemisphere (from 0.43 to $0.46 ; 1$ case exceeding the threshold) and reduced in the right hemisphere (from 0.42 to $0.38 ; 2$ case exceeding the threshold). The negative correlations increased in both left (from -0.38 to $-0.41 ; 1$ case exceeding the threshold) and right hemispheres (from -0.32 to $-0.38 ; 2$ case exceeding the threshold).

\section{Discussion}

Although methodological advances in neuroimaging have ignited great interest in macrostructural properties of the cerebral cortex and microstructural properties of WM throughout life, intracortical lifespan changes have mainly eluded close examination. This is in contrast to the fact that the unfolding of cortical myelination and demyelination from birth to senium has interested neuroscientists for more than a century (Kaes, 1907). Here, using a myelin-mapping approach (Glasser and Van Essen, 2011), we characterized the degree of intracortical myelin in 339 subjects $8-83$ years of age. We found inverse U-shaped lifespan trajectories across the cortex, with substantial heterogeneity across different regions. Association cortices tended to show the most curved trajectories, indicating protracted intracortical myelin development and vulnerability to aging. Similar effects 
were seen for DTI-derived MD. Myelin content correlated with within-subject variability on a speeded performance task signaling behavioral correlates of individual differences in cortical myelin. The results suggest that myelin mapping in vivo detects effects of age on intracortical myelin grade in development and aging and, importantly, is associated with cognition. Therefore, mapping myelin by use of $\mathrm{T} 1 \mathrm{w} / \mathrm{T} 2 \mathrm{w}$ MRI could be a valuable neuroscientific tool for studying effects on intracortical myelin content across various populations and conditions.

\section{Lifespan changes in \\ intracortical myelination}

The location and extent of important cortical areas characterized using highresolution T1w images in marmosets and $\mathrm{T} 1 \mathrm{w} / \mathrm{T} 2 \mathrm{w}$ ratio maps in humans agree closely in direct and indirect comparisons, respectively, with myelin histology (Bock et al., 2011; Glasser and Van Essen, 2011). Although additional validation is required, these findings provide support of the interpretation of $\mathrm{T} 1 \mathrm{w} / \mathrm{T} 2 \mathrm{w}$ ratio as an estimate of myelin. Our T1w/T2w ratio myelin maps generally demonstrate inverted U-shaped trajectories, indicating a three-staged process of cortical myelin changes: an accelerated myelination process until $\sim 30$ years of age, followed by a period of relative stability, before a decrease in myelin content from the late 50s. DTI-derived MD, partly influenced by myelin (Beaulieu, 2002), mapped from the same vertices as the $\mathrm{T} 1 \mathrm{w} / \mathrm{T} 2 \mathrm{w}$ ratio generally showed U-shaped patterns, although demonstrating less maturational effects in some regions. All findings were statistically independent of concurrent cortical thinning. The results accord with the seminal histology study by Yakovlev and Lecours (1967), who reported an increase of myelinated fibers in the association cortices until the third decade and possibly beyond. However, discrepancies with lifespan histology studies of restricted regions exist (Lintl and Braak, 1983; Benes et al., 1994). For example, Benes (1989) reported stable myelination of the cingulate cortices from the second decade. However, the relative sparsity of data points in lower or upper age ranges in these studies limits conclusions regarding lifespan trajectories. Studies using a combination of histology and imaging would be particularly informative in untangling these findings and in further substantiating the link between $\mathrm{T} 1 \mathrm{w} / \mathrm{T} 2 \mathrm{w}$ ratio and myelin.

The $\mathrm{T} 1 \mathrm{w} / \mathrm{T} 2 \mathrm{w}$ ratio approach refines our efforts using $\mathrm{T} 1 \mathrm{w}$ intensity to trace cortical changes in an overlapping sample

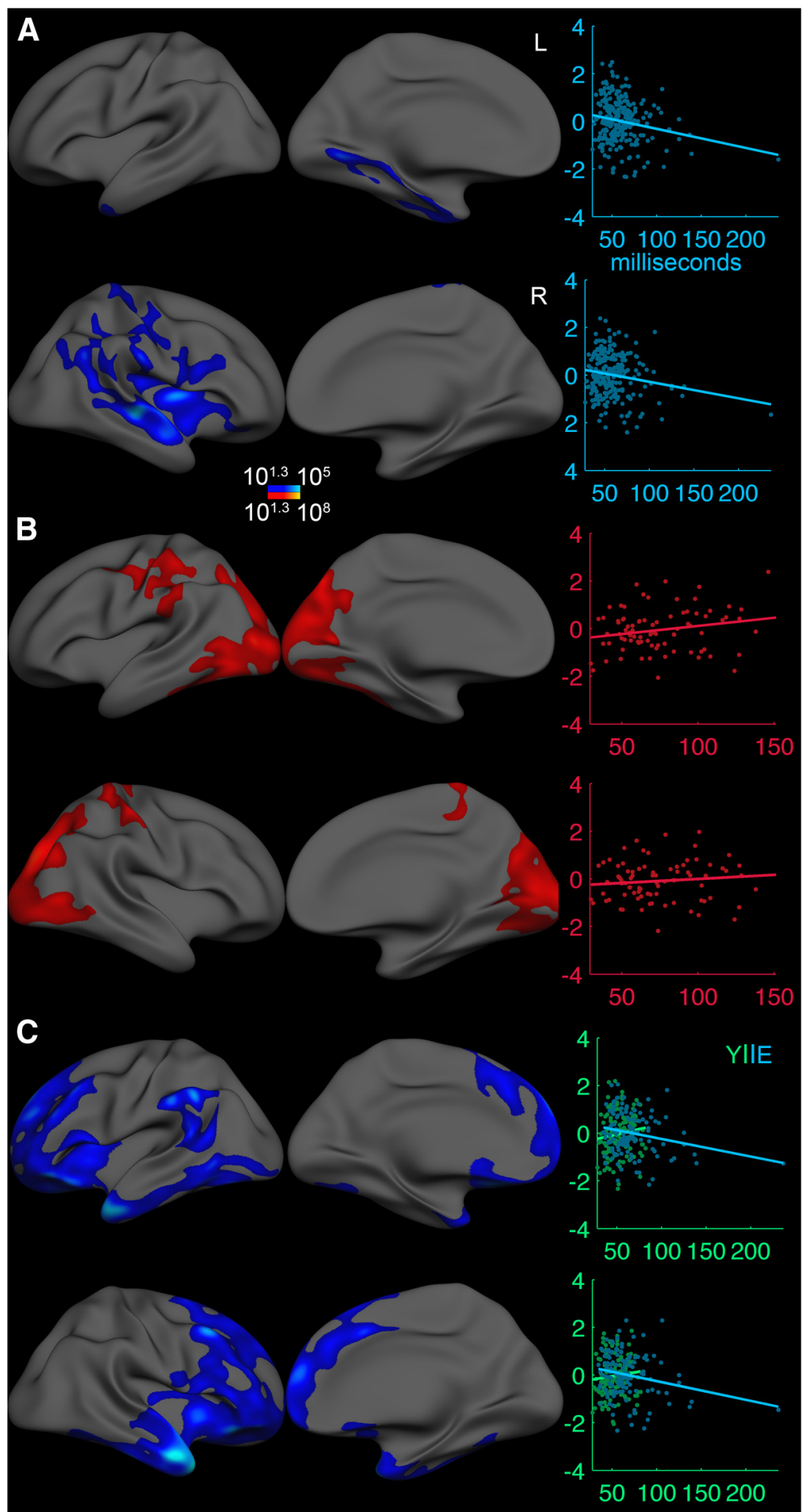

Figure 9. The relationship between T1w/T2w ratio and IIV. Left, $p$-values maps showing the relationship between T1w/T2w ratio and IIV in the adults $(\boldsymbol{A})$, theyoung $(\boldsymbol{B})$, and the interaction between age and IIV in adults ( $(\boldsymbol{)}$. The effects are corrected for multiple comparisons, but actual $p$-values are shown. See Table 2 for clusterwise $p$-values. Right, Scatterplots illustrating the surface-based analyses; values are $z$-values of mean residuals after excluding studentized deleted residuals exceeding \pm 2 and regressing T1w/T2w on sex, age, T2w matrix, mRT, FIQ, and thickness (please see Materials and Methods for details). Y, young adults ( $<52$ years); E, elderly ( $\geq 52$ years).

(Westlye et al., 2010b). As in the present study, a three-phasic function was delineated, with the greatest age-related decrease observed from the late 50s. However, peaks were estimated to be earlier; for example, the superior parietal cortex peaked in the 

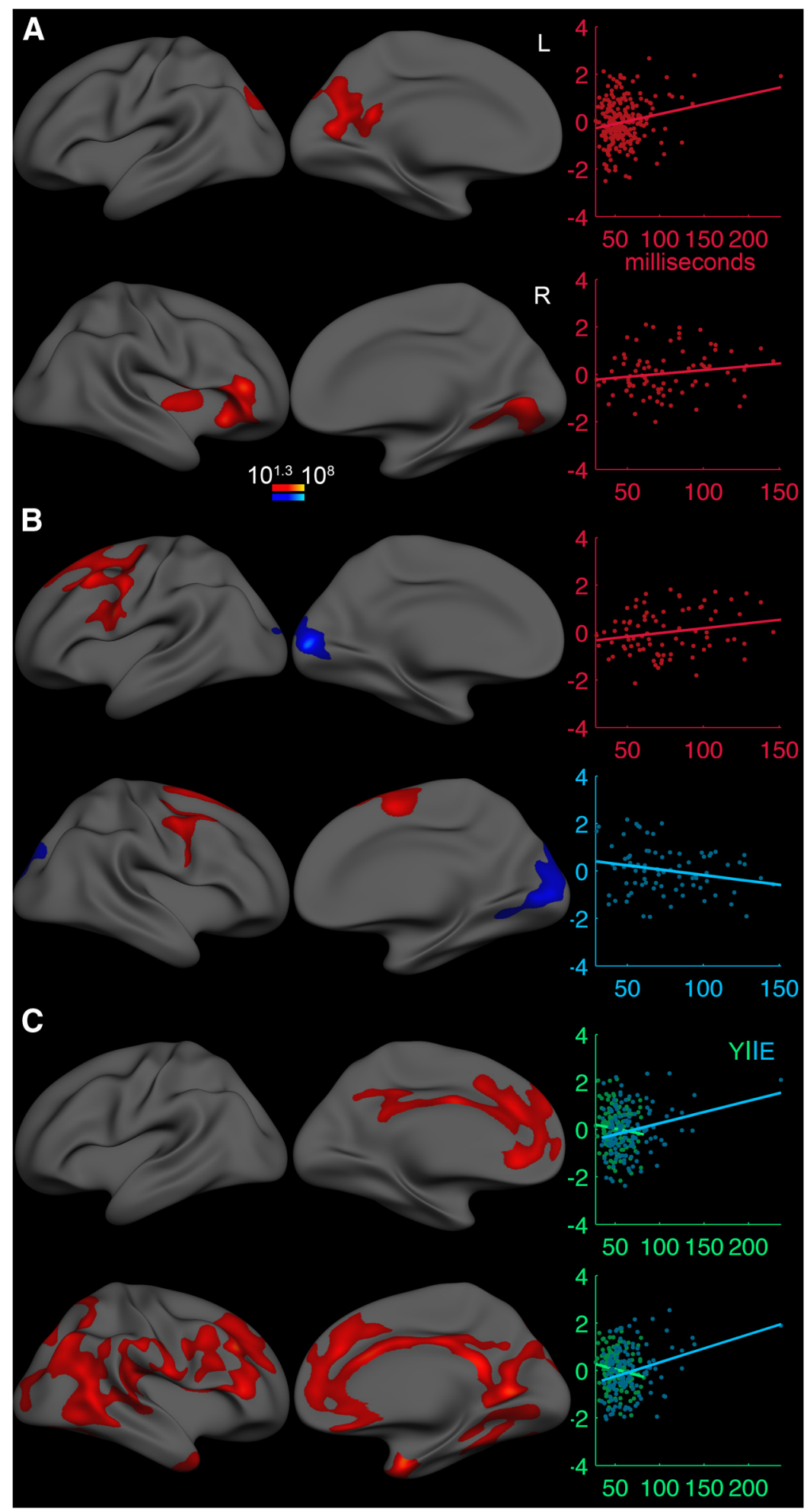

Figure 10. Relationship between MD and IIV. Left, $P$-values maps showing the relationship between T1w/T2w ratio and IIV in the adults $(\boldsymbol{A})$, the young $(\boldsymbol{B})$, and the interaction between age and IIV in adults $(\boldsymbol{C})$. The effects are corrected for multiple comparisons, but actual $p$-values are shown. See Table 2 for clusterwise $p$-values. Right, Scatterplots illustrating the surface-based analyses; values are $z$-values of mean residuls after excluding studentized deleted residuals exceeding \pm 2 and regressing MD on sex, age, $m R T$, FIQ, and thickness (see Materials and Methods for details). Please note that in $\boldsymbol{B}$, scatterplots are only shown for the positive cluster in the left hemisphere and for the negative cluster in the right hemisphere. $Y$, young adults ( $<52$ years); $E$, elderly ( $\geq 52$ years).

middle of the second decade of life. In addition to minor processing differences, Westlye et al. (2010b) normalized the T1w signal at each voxel by CSF signal intensity. The local normalization by the corresponding voxel in the $\mathrm{T} 2 \mathrm{w}$ image might render the $\mathrm{T} 1 \mathrm{w} /$
T2w method more accurate. However, although the bias field in the T1w and T2w sequences are highly correlated, they are not identical (Glasser et al., 2013), which may favor the use of only T1w intensity either normalized by CSF or as a GM/WM ratio (Westlye et al., 2009b). Longitudinal imaging studies using a multimodal approach will help to settle the observed disagreements.

\section{Cognitive correlates}

IIV reflects performance fluctuations during a single task session (Stuss et al., 2003) and is increased in, for example, attention deficit hyperactivity disorder and mild dementia (Hultsch et al., 2000; Castellanos and Tannock, 2002). We recently related greater IIV to widespread WM integrity reductions (Fjell et al., 2011; Tamnes et al., 2012). Here, we link IIV to degree of myelin within cortical regions. The effects were independent of general intellectual abilities and were right lateralized, which is consistent with a greater specialization of the right cortices for visuospatial attention (Mesulam, 1981; Corbetta et al., 1993). The findings concur with correlations between aging-related myelin defects in the prefrontal cortex and cognitive impairment in primates (Peters and Sethares, 2002). In humans, Blackmon et al. (2011) used a ratio of GM and WM T1w intensity and found left-lateralized correlations with verbal working memory performance. Here, we extend this finding by associating cognitive functioning specifically to cortical myelin content. A potential mechanism relates reduced myelin to decreased structural and functional connectivity (Garrett et al., 2011), increasing neural noise (MacDonald et al., 2009). We have previously reported cortical thickness-attention correlations in an overlapping sample (Westlye et al., 2011), effects possibly influenced by myelin changes. Although speeded tasks constitute a prime candidate for studying cognition-myelin relationships, future studies should assess how cortical myelin might have implications for other aspects of cognition, especially in aging (Salthouse, 1996).

As expected based on our previous WM studies, the relationship between IIV and intracortical microstructure was strongest in the elderly ( $\geq 52$ years). The results suggest that the weakest relationship between IIV and microstructure manifest in groups of participants showing less variance in microstructural properties and IIV, whereas a relationship appeared in elderly participants, in whom individual differences may be 
larger. However, the mechanisms underlying age-related alterations on myelin remain poorly understood. A host of processes disrupting myelin have been reported in aging primates, for example, increased thickness of myelin sheaths (Peters et al., 2001) and formation of myelin balloons (Feldman and Peters, 1998). It is likely that these changes differ compared with the myelination occurring during development (Tau and Peterson, 2010). Such possible differential effects during development and aging may have different cognitive correlates. Moreover, we mainly observed that increased intracortical myelin (higher $\mathrm{T} 1 \mathrm{w} / \mathrm{T} 2 \mathrm{w}$ ratio or lower MD) related to less variable performance. This relationship is consistent with our hypothesis based on the beneficial effects of myelin for neural conduction (Zalc and Colman, 2000). However, the opposite relationship was found in the young subsample covering posterior regions. The effects could relate to greater maturational compared with aging-related changes (Tamnes et al., 2013), increasing the age term in our model and thereby reducing residual variance. Although complex relations between structure and function exist in development (Shaw et al., 2006), the current data do not allow us to rule out regional maturational effects of myelin beyond improving conduction velocity and timing (Fields, 2008).

The adult IIV-T1w/T2w associations mostly disappeared when accounting for WM myelin levels. This suggests concurrent WM and GM axonal aging processes with similar behavior correlates (Peters and Kemper, 2012), but awaits exploration in clinical conditions (Grydeland et al., 2010). The WM curves, generally in accordance with previous WM DTI findings (Westlye et al., 2010a; Lebel et al., 2012), showed a somewhat less protracted development compared with GM. Both curves generally evidenced decline from the late 50s, but were more pronounced in WM. We expected relatively similar age effects (Westlye et al., 2010a, 2010b) and the slight discrepancies in age associations might stem from greater amount of myelin in WM and increased WM/GM boundary blurring with age (Salat et al., 2009), probably with a larger impact on GM values, potentially rendering the WM age trajectories more accurate.

\section{Limitations and future directions of research}

Although T1w and T2w images largely reflect myelin (Eickhoff et al., 2005), cell density and iron (Fukunaga et al., 2010) likely contribute. Future studies will benefit from high-resolution scans. Thin and heavily myelinated areas such as the pericalcarine cortex may suffer more from partial-volume effects (Glasser and Van Essen, 2011), potentially yielding incorrect $\mathrm{T} 1 \mathrm{w} / \mathrm{T} 2 \mathrm{w}$ ratio and MD values. The decrease in pericalcarine cortical thickness through the lifespan (Westlye et al., 2009b) may exacerbate the effects with age and cause the lack of decrease in myelin with age observed here. Similarly, the $2 \mathrm{~mm}$ isotropic resolution of the DTI images causes partial-volume of tissue types when assessing thin cortices. In addition, these cross-sectional findings should be confirmed by longitudinal change measurements.

\section{Conclusion}

We mapped intracortical myelin through the lifespan using T1/ T2w MRI intensities and generally observed a three-phasic relationship in which myelin increased until $\sim 30$ years of age and remained relatively stable before a decline started around the end of the 50s. A relationship between intracortical myelin and intrasession performance variability was observed in widespread regions. This link was strongest with increasing age, suggesting that aging-related intracortical myelin changes contribute to increased IIV. Corresponding findings were generally observed for
MD sampled from the same vertices. The results suggest that myelin mapping by MRI constitute a viable method for studying intracortical myelin differences and cognition in development and aging. The relatively short scan times and conventional protocols also hold hope for potential application in aiding detection (Grydeland et al., 2013) in clinical populations, including dementia (Bosch et al., 2012), schizophrenia (Alexander-Bloch et al., 2013), and multiple sclerosis (Hulst and Geurts, 2011).

\section{References}

Abe O, Yamasue H, Aoki S, Suga M, Yamada H, Kasai K, Masutani Y, Kato N, Kato N, Ohtomo K (2008) Aging in the CNS: comparison of gray/white matter volume and diffusion tensor data. Neurobiol Aging 29:102-116. CrossRef Medline

Alexander-Bloch AF, Vértes PE, Stidd R, Lalonde F, Clasen L, Rapoport J, Giedd J, Bullmore ET, Gogtay N (2013) The anatomical distance of functional connections predicts brain network topology in health and schizophrenia. Cereb Cortex 23:127-138. CrossRef Medline

Bartzokis G (2004) Age-related myelin breakdown: a developmental model of cognitive decline and Alzheimer's disease. Neurobiol Aging 25:5-18; author reply 49-62. Medline

Bartzokis G, Beckson M, Lu PH, Nuechterlein KH, Edwards N, Mintz J (2001) Age-related changes in frontal and temporal lobe volumes in men: a magnetic resonance imaging study. Arch Gen Psychiatr 58:461465. Medline

Beaulieu C (2002) The basis of anisotropic water diffusion in the nervous system-a technical review. NMR Biomed 15:435-455. CrossRef Medline

Beck AT, Steer R (1987) Beck depression inventory scoring manual. New York: The Psychological Corporation.

Benes FM (1989) Myelination of cortical-hippocampal relays during late adolescence. Schizophr Bull 15:585-593. CrossRef Medline

Benes FM, Turtle M, Khan Y, Farol P (1994) Myelination of a key relay zone in the hippocampal formation occurs in the human brain during childhood, adolescence, and adulthood. Arch Gen Psychiatr 51:477-484. Medline

Blackmon K, Halgren E, Barr WB, Carlson C, Devinsky O, DuBois J, Quinn BT, French J, Kuzniecky R, Thesen T (2011) Individual differences in verbal abilities associated with regional blurring of the left gray and white matter boundary. J Neurosci 31:15257-15263. CrossRef Medline

Bock NA, Hashim E, Kocharyan A, Silva AC (2011) Visualizing myeloarchitecture with magnetic resonance imaging in primates. Ann N Y Acad Sci 1225(suppl 1):E171-E181. CrossRef Medline

Bosch B, Arenaza-Urquijo EM, Rami L, Sala-Llonch R, Junqué C, SoléPadullés C, Peña-Gómez C, Bargalló N, Molinuevo JL, Bartrés-Faz D (2012) Multiple DTI index analysis in normal aging, amnestic MCI and AD. Relationship with neuropsychological performance. Neurobiol Aging 33:61-74. CrossRef Medline

Carreiras M, Seghier ML, Baquero S, Estévez A, Lozano A, Devlin JT, Price CJ (2009) An anatomical signature for literacy. Nature 461:983-986. CrossRef Medline

Castellanos FX, Tannock R (2002) Neuroscience of attention-deficit/hyperactivity disorder: the search for endophenotypes. Nat Rev Neurosci 3:617-628. CrossRef Medline

Concha L, Gross DW, Wheatley BM, Beaulieu C (2006) Diffusion tensor imaging of time-dependent axonal and myelin degradation after corpus callosotomy in epilepsy patients. Neuroimage 32:1090-1099. CrossRef Medline

Corbetta M, Miezin FM, Shulman GL, Petersen SE (1993) A PET study of visuospatial attention. J Neurosci 13:1202-1226. Medline

Dale AM, Fischl B, Sereno MI (1999) Cortical surface-based analysis. I. Segmentation and surface reconstruction. Neuroimage 9:179-194. CrossRef Medline

Debener S, Ullsperger M, Siegel M, Fiehler K, von Cramon DY, Engel AK (2005) Trial-by-trial coupling of concurrent electroencephalogram and functional magnetic resonance imaging identifies the dynamics of performance monitoring. J Neurosci 25:11730-11737. CrossRef Medline

Desikan RS, Ségonne F, Fischl B, Quinn BT, Dickerson BC, Blacker D, Buckner RL, Dale AM, Maguire RP, Hyman BT, Albert MS, Killiany RJ (2006) An automated labeling system for subdividing the human cerebral cortex on MRI scans into gyral based regions of interest. Neuroimage 31:968980. CrossRef Medline 
Eickhoff S, Walters NB, Schleicher A, Kril J, Egan GF, Zilles K, Watson JD, Amunts K (2005) High-resolution MRI reflects myeloarchitecture and cytoarchitecture of human cerebral cortex. Hum Brain Mapp 24:206215. CrossRef Medline

Eriksen BA, Eriksen CW (1974) Effects of noise letters upon the identification of a target letter in a nonsearch task. Perception \& Psychophysics 16:143-149. CrossRef

Feldman ML, Peters A (1998) Ballooning of myelin sheaths in normally aged macaques. J Neurocytol 27:605-614. CrossRef Medline

Fields RD (2008) White matter in learning, cognition and psychiatric disorders. Trends Neurosci 31:361-370. CrossRef Medline

Fischl B, Dale AM (2000) Measuring the thickness of the human cerebral cortex from magnetic resonance images. Proc Natl Acad Sci U S A 97: 11050-11055. CrossRef Medline

Fischl B, Sereno MI, Dale AM (1999a) Cortical surface-based analysis. II: Inflation, flattening, and a surface-based coordinate system. Neuroimage 9:195-207. CrossRef Medline

Fischl B, Sereno MI, Tootell RB, Dale AM (1999b) High-resolution intersubject averaging and a coordinate system for the cortical surface. Hum Brain Mapp 8:272-284. CrossRef Medline

Fischl B, Salat DH, Busa E, Albert M, Dieterich M, Haselgrove C, van der Kouwe A, Killiany R, Kennedy D, Klaveness S, Montillo A, Makris N, Rosen B, Dale AM (2002) Whole brain segmentation: automated labeling of neuroanatomical structures in the human brain. Neuron 33:341355. CrossRef Medline

Fischl B, Salat DH, van der Kouwe AJ, Makris N, Ségonne F, Quinn BT, Dale AM (2004a) Sequence-independent segmentation of magnetic resonance images. Neuroimage 23(suppl 1):S69-S84.

Fischl B, van der Kouwe A, Destrieux C, Halgren E, Ségonne F, Salat DH, Busa E, Seidman LJ, Goldstein J, Kennedy D, Caviness V, Makris N, Rosen B, Dale AM (2004b) Automatically parcellating the human cerebral cortex. Cereb Cortex 14:11-22. CrossRef Medline

Fjell AM, Westlye LT, Amlien I, Espeseth T, Reinvang I, Raz N, Agartz I, Salat DH, Greve DN, Fischl B, Dale AM, Walhovd KB (2009) High consistency of regional cortical thinning in aging across multiple samples. Cereb Cortex 19:2001-2012. CrossRef Medline

Fjell AM, Walhovd KB, Westlye LT, Østby Y, Tamnes CK, Jernigan TL, Gamst A, Dale AM (2010) When does brain aging accelerate? Dangers of quadratic fits in cross-sectional studies. Neuroimage 50:1376-1383. CrossRef Medline

Fjell AM, Westlye LT, Amlien IK, Walhovd KB (2011) Reduced white matter integrity is related to cognitive instability. J Neurosci 31:18060-18072. CrossRef Medline

Folstein MF, Folstein SE, McHugh PR (1975) "Mini-mental state". A practical method for grading the cognitive state of patients for the clinician. J Psychiatr Res 12:189-198. CrossRef Medline

Fukunaga M, Li TQ, van Gelderen P, de Zwart JA, Shmueli K, Yao B, Lee J, Maric D, Aronova MA, Zhang G, Leapman RD, Schenck JF, Merkle H, Duyn JH (2010) Layer-specific variation of iron content in cerebral cortex as a source of MRI contrast. Proc Natl Acad Sci U S A 107:3834-3839. CrossRef Medline

Garrett DD, Kovacevic N, McIntosh AR, Grady CL (2011) The importance of being variable. J Neurosci 31:4496-4503. CrossRef Medline

Glasser MF, Van Essen DC (2011) Mapping human cortical areas in vivo based on myelin content as revealed by T1- and T2-weighted MRI. J Neurosci 31:11597-11616. CrossRef Medline

Glasser MF, Goyal MS, Preuss TM, Raichle ME, Van Essen DC (2013) Trends and properties of human cerebral cortex: correlations with cortical myelin content. Neuroimage. Advance online publication. doi: 10.1016/j.neuroimage.2013.03.060. CrossRef Medline

Gogtay N, Giedd JN, Lusk L, Hayashi KM, Greenstein D, Vaituzis AC, Nugent TF 3rd, Herman DH, Clasen LS, Toga AW, Rapoport JL, Thompson PM (2004) Dynamic mapping of human cortical development during childhood through early adulthood. Proc Natl Acad Sci U S A 101:8174-8179. CrossRef Medline

Greve DN, Fischl B (2009) Accurate and robust brain image alignment using boundary-based registration. Neuroimage 48:63-72. CrossRef Medline

Grydeland H, Walhovd KB, Westlye LT, Due-Tønnessen P, Ormaasen V, Sundseth Ø, Fjell AM (2010) Amnesia following herpes simplex encephalitis: diffusion-tensor imaging uncovers reduced integrity of normalappearing white matter. Radiology 257:774-781. CrossRef Medline
Grydeland H, Westlye LT, Walhovd KB, Fjell AM (2013) Improved prediction of Alzheimer's disease with longitudinal white matter/gray matter contrast changes. Hum Brain Mapp 34:2775-2785. CrossRef Medline

Hagler DJ Jr, Saygin AP, Sereno MI (2006) Smoothing and cluster thresholding for cortical surface-based group analysis of fMRI data. Neuroimage 33:1093-1103. CrossRef Medline

Hulst HE, Geurts JJ (2011) Gray matter imaging in multiple sclerosis: what have we learned? BMC Neurol 11:153. CrossRef Medline

Hultsch DF, MacDonald SW, Hunter MA, Levy-Bencheton J, Strauss E (2000) Intraindividual variability in cognitive performance in older adults: comparison of adults with mild dementia, adults with arthritis, and healthy adults. Neuropsychology 14:588-598. CrossRef Medline

Jenkinson M, Smith S (2001) A global optimisation method for robust affine registration of brain images. Med Image Anal 5:143-156. CrossRef Medline

Kaes T (1907) Die Grosshirnrinde des Menschen in ihren Massen und in ihrem Fasergehalt. Jena: Fischer.

Kochunov P, Glahn DC, Lancaster J, Thompson PM, Kochunov V, Rogers B, Fox P, Blangero J, Williamson DE (2011) Fractional anisotropy of cerebral white matter and thickness of cortical gray matter across the lifespan. Neuroimage 58:41-49. CrossRef Medline

Koo BB, Hua N, Choi CH, Ronen I, Lee JM, Kim DS (2009) A framework to analyze partial volume effect on gray matter mean diffusivity measurements. Neuroimage 44:136-144. CrossRef Medline

Lebel C, Beaulieu C (2011) Longitudinal development of human brain wiring continues from childhood into adulthood. J Neurosci 31:1093710947. CrossRef Medline

Lebel C, Gee M, Camicioli R, Wieler M, Martin W, Beaulieu C (2012) Diffusion tensor imaging of white matter tract evolution over the lifespan. Neuroimage 60:340-352. CrossRef Medline

Lintl P, Braak H (1983) Loss of intracortical myelinated fibers: a distinctive age-related alteration in the human striate area. Acta Neuropathol 61: 178-182. CrossRef Medline

MacDonald SW, Li SC, Bäckman L (2009) Neural underpinnings of withinperson variability in cognitive functioning. Psychol Aging 24:792-808. CrossRef Medline

Mesulam MM (1981) A cortical network for directed attention and unilateral neglect. Ann Neurol 10:309-325. CrossRef Medline

Nieuwenhuys R (2013) The myeloarchitectonic studies on the human cerebral cortex of the Vogt-Vogt school, and their significance for the interpretation of functional neuroimaging data. Brain Struct Funct 218:303-352. CrossRef Medline

Panizzon MS, Fennema-Notestine C, Kubarych TS, Chen CH, Eyler LT, Fischl B, Franz CE, Grant MD, Hamza S, Jak A, Jernigan TL, Lyons MJ, Neale MC, Prom-Wormley EC, Seidman L, Tsuang MT, Wu H, Xian H, Dale AM, Kremen WS (2012) Genetic and environmental influences of white and gray matter signal contrast: a new phenotype for imaging genetics? Neuroimage 60:1686-1695. CrossRef Medline

Paus T (2005) Mapping brain maturation and cognitive development during adolescence. Trends Cogn Sci 9:60-68. CrossRef Medline

Peters A, Kemper T (2012) A review of the structural alterations in the cerebral hemispheres of the aging rhesus monkey. Neurobiol Aging 33: 2357-2372. CrossRef Medline

Peters A, Sethares C (2002) Aging and the myelinated fibers in prefrontal cortex and corpus callosum of the monkey. J Comp Neurol 442:277-291. CrossRef Medline

Peters A, Sethares C, Killiany RJ (2001) Effects of age on the thickness of myelin sheaths in monkey primary visual cortex. J Comp Neurol 435:241248. CrossRef Medline

Pierpaoli C, Jezzard P, Basser PJ, Barnett A, Di Chiro G (1996) Diffusion tensor MR imaging of the human brain. Radiology 201:637-648. Medline

Reese TG, Heid O, Weisskoff RM, Wedeen VJ (2003) Reduction of eddycurrent-induced distortion in diffusion MRI using a twice-refocused spin echo. Magn Reson Med 49:177-182. CrossRef Medline

Salat DH, Lee SY, van der Kouwe AJ, Greve DN, Fischl B, Rosas HD (2009) Age-associated alterations in cortical gray and white matter signal intensity and gray to white matter contrast. Neuroimage 48:21-28. CrossRef Medline

Salthouse TA (1996) The processing-speed theory of adult age differences in cognition. Psychol Rev 103:403-428. CrossRef Medline

Ségonne F, Dale AM, Busa E, Glessner M, Salat D, Hahn HK, Fischl B (2004) 
A hybrid approach to the skull stripping problem in MRI. Neuroimage 22:1060-1075. CrossRef Medline

Shaw P, Greenstein D, Lerch J, Clasen L, Lenroot R, Gogtay N, Evans A, Rapoport J, Giedd J (2006) Intellectual ability and cortical development in children and adolescents. Nature 440:676-679. CrossRef Medline

Sigalovsky IS, Fischl B, Melcher JR (2006) Mapping an intrinsic MR property of gray matter in auditory cortex of living humans: a possible marker for primary cortex and hemispheric differences. Neuroimage 32:15241537. CrossRef Medline

Sled JG, Zijdenbos AP, Evans AC (1998) A nonparametric method for automatic correction of intensity nonuniformity in MRI data. IEEE Trans Med Imaging 17:87-97. CrossRef Medline

Smith SM (2002) Fast robust automated brain extraction. Hum Brain Mapp 17:143-155. CrossRef Medline

Smith SM, Jenkinson M, Woolrich MW, Beckmann CF, Behrens TE, Johansen-Berg H, Bannister PR, De Luca M, Drobnjak I, Flitney DE, Niazy RK, Saunders J, Vickers J, Zhang Y, De Stefano N, Brady JM, Matthews PM (2004) Advances in functional and structural MR image analysis and implementation as FSL. Neuroimage 23(suppl 1):S208-S219. CrossRef Medline

Song SK, Sun SW, Ramsbottom MJ, Chang C, Russell J, Cross AH (2002) Dysmyelination revealed through MRI as increased radial (but unchanged axial) diffusion of water. Neuroimage 17:1429-1436. CrossRef Medline

Song SK, Yoshino J, Le TQ, Lin SJ, Sun SW, Cross AH, Armstrong RC (2005) Demyelination increases radial diffusivity in corpus callosum of mouse brain. Neuroimage 26:132-140. CrossRef Medline

Sowell ER, Peterson BS, Thompson PM, Welcome SE, Henkenius AL, Toga AW (2003) Mapping cortical change across the human life span. Nat Neurosci 6:309-315. CrossRef Medline

Stuss DT, Murphy KJ, Binns MA, Alexander MP (2003) Staying on the job: the frontal lobes control individual performance variability. Brain 126: 2363-2380. CrossRef Medline

Tamnes CK, Østby Y, Fjell AM, Westlye LT, Due-Tønnessen P, Walhovd KB (2010) Brain maturation in adolescence and young adulthood: regional age-related changes in cortical thickness and white matter volume and microstructure. Cereb Cortex 20:534-548. CrossRef Medline

Tamnes CK, Fjell AM, Westlye LT, Østby Y, Walhovd KB (2012) Becoming consistent: developmental reductions in intraindividual variability in reaction time are related to white matter integrity. J Neurosci 32:972-982. CrossRef Medline

Tamnes CK, Walhovd KB, Dale AM, Østby Y, Grydeland H, Richardson G, Westlye LT, Roddey JC, Hagler DJ Jr, Due-Tønnessen P, Holland D, Fjell
AM (2013) Brain development and aging: overlapping and unique patterns of change. Neuroimage 68:63-74. CrossRef Medline

Tau GZ, Peterson BS (2010) Normal development of brain circuits. Neuropsychopharmacology 35:147-168. CrossRef Medline

Vogt O (1910) The myeloarchitectonic tesselated mosaicism of the human front-brain. J für Psychologie und Neurologie 15:221-232.

Wechsler D (1999) Wechsler abbreviated scale of intelligence. San Antonio, TX: The Psychological Corporation.

Westlye LT, Walhovd KB, Bjørnerud A, Due-Tønnessen P, Fjell AM (2009a) Error-related negativity is mediated by fractional anisotropy in the posterior cingulate gyrus-a study combining diffusion tensor imaging and electrophysiology in healthy adults. Cereb Cortex 19:293-304. CrossRef Medline

Westlye LT, Walhovd KB, Dale AM, Espeseth T, Reinvang I, Raz N, Agartz I, Greve DN, Fischl B, Fjell AM (2009b) Increased sensitivity to effects of normal aging and Alzheimer's disease on cortical thickness by adjustment for local variability in gray/white contrast: a multi-sample MRI study. Neuroimage 47:1545-1557. CrossRef Medline

Westlye LT, Walhovd KB, Dale AM, Bjørnerud A, Due-Tønnessen P, Engvig A, Grydeland H, Tamnes CK, Østby Y, Fjell AM (2010a) Life-span changes of the human brain white matter: diffusion tensor imaging (DTI) and volumetry. Cereb Cortex 20:2055-2068. CrossRef Medline

Westlye LT, Walhovd KB, Dale AM, Bjørnerud A, Due-Tønnessen P, Engvig A, Grydeland H, Tamnes CK, Østby Y, Fjell AM (2010b) Differentiating maturational and aging-related changes of the cerebral cortex by use of thickness and signal intensity. Neuroimage 52:172-185. CrossRef Medline

Westlye LT, Grydeland H, Walhovd KB, Fjell AM (2011) Associations between regional cortical thickness and attentional networks as measured by the attention network test. Cereb Cortex 21:345-356. CrossRef Medline

Woolrich MW, Jbabdi S, Patenaude B, Chappell M, Makni S, Behrens T, Beckmann C, Jenkinson M, Smith SM (2009) Bayesian analysis of neuroimaging data in FSL. Neuroimage 45:S173-186. CrossRef Medline

Yakovlev PI, Lecours A-R (1967) The myelogenic cycles of regional maturation of the brain. In: Regional development of the brain in early life (Minkowski A, ed), pp 3-70. Oxford and Edinburg: Blackwell Scientific Publications.

Yoshiura T, Higano S, Rubio A, Shrier DA, Kwok WE, Iwanaga S, Numaguchi Y (2000) Heschl and superior temporal gyri: low signal intensity of the cortex on T2-weighted MR images of the normal brain. Radiology 214: 217-221. Medline

Zalc B, Colman DR (2000) Origins of vertebrate success. Science 288:271272. Medline 